\title{
Challenges in developing a computationally efficient plant physiological height-class- structured forest model
}

\section{Authors: M. Scherstjanoi, J.O. Kaplan, B. Poulter, \& H. Lischke}

This is the author's version of a work that was accepted for publication in Ecological Complexity. Changes resulting from the publishing process, such as peer review, editing, corrections, structural formatting, and other quality control mechanisms may not be reflected in this document. Changes may have been made to this work since it was submitted for publication. A definitive version was subsequently published in Ecological Complexity, Volume 19 (September 2014) DOI \# 10.1016/ j.ecocom.2014.05.009

Scherstjanoi, M., J. O. Kaplan, B. Poulter, and H. Lischke. "Challenges in developing a computationally efficient plant physiological height-class-structured forest model." Ecological Complexity 19 (2014): 96-110. http://dx.doi.org/10.1016/j.ecocom.2014.05.009. 


\title{
Challenges in developing a computationally efficient plant physiological height-class- structured forest model
}

\author{
M. Scherstjanoi \& H. Lischke: Dynamic Macroecology, Landscape Dynamics, Swiss Federal Research Institute WSL, Zürcherstr. III, CH-8903 Birmensdorf, Switzerland \\ J.0. Kaplan: University of Lausanne, Geopolis, Quartier Mouline, Institute of Earth Surface Dynamics, CH-1015 Lausanne, Switzerland \\ B. Poulter. Montana State University, Department of Ecology, Bozeman, MT 59717, USA
}

\begin{abstract}
Ongoing and future climate change may be of sufficient magnitude to significantly impact global forest ecosystems. In order to anticipate the potential range of changes to forests in the future and to better understand the development and state of forest ecosystems at present, a variety of forest ecosystem models of varying complexity have been developed over the past 40 years. While most of these models focus on representing either forest demographics including age and height structure, or forest biogeochemistry including plant physiology and ecosystem carbon cycling, it is increasingly seen as crucial that forest ecosystem models include equally good representations of both. However, only few models currently include detailed representations of both biogeochemistry and demographics, and those mostly have high computational demands. Here, we present TreeM-LPJ, a first step towards a new, computationally efficient forest dynamics model. We combine the height-class scheme of the forest landscape model TreeMig with the biogeochemistry of the dynamic global vegetation model LPJGUESS. The resulting model is able to simulate forest growth by considering vertical spatial variability without stochastic functions, considerably reducing computational demand. Discretization errors are kept small by using a numerical algorithm that extrapolates growth success in height, and thereby dynamically updates the state variables of the trees in the different height classes. We demonstrate TreeM-LPJ in an application on a transect in the central Swiss Alps where we show results from the new model compare favorably with the more complex LPJ-GUESS. TreeM-LPJ provides a combination of biological detail and computational efficiency that can serve as a useful basis for large-scale vegetation modeling.
\end{abstract}

\section{Introduction}

Process models of forest dynamics trade off ecological complexity with computational efficiency (Lischke et al., 1998). Early models tracked individual trees' establishment, growth and mortality (Botkin et al., 1972; Shugart and West, 1977), while later forest gap models (Shugart, 1984; Bugmann and Cramer, 1998) replaced individuals with age-based cohorts (Bugmann, 1996). Both approaches used empirical growth formulations. At global scales, empirical growth was replaced by first-order processes describing photosynthesis and transpiration, with vegetation generalized by populations rather than individuals or cohorts (Sitch et al., 2003; Krinner et al., 2005). Vegetation structure was then reintroduced into the global scale models by hybrid approaches, e.g. LPJ-GUESS (Smith et al., 2001; Hickler et al., 2004), or SEIB-DGVM (Sato et al., 2007). These hybrid models combine ecophysiological functions with gap model approaches, at the cost, however, of computing efficiency, grid cell resolution, or model extent. Gap models are more tractable for simulating forest structural dynamics and forest management than global vegetation models, but require multiple simulations per grid cell to average stochasticity from establishment and mortality, typically 100-200 replicate patches (Smith et al., 2008;

Bugmann, 1994). The problem of successive repetitions has been solved in different ways. On the basis of forests generalized as single plant ecosystems (Chertov et al., 1999), Chertov et al. (2006) use the information of ecophysiological processes upscaled in parameters of biological productivity and main dendrometric and population character-istics to enable simulations from stand to regional scale. Moorcroft et al. (2001) upscaled tree size and gap age, and applied the approach to the DGVM ED. Strigul et al. (2008) developed a method to generalize canopy structure properties from the individual tree 
information in gap models. Another solution that leads to the distribution of light properties was developed for the forest landscape model TreeMig, which uses a distributional approach for light within discrete height classes. This allows spatial simulations that include dispersal and migration to take place within a computationally efficient framework (Lischke et al., 1998, 2006a).

Apart from upscaling gap model approaches, various attempts exist to generally make forest models more computationally efficient. Yang et al. (2011) successfully increased the efficiency of a forest landscape model using hash tables and run-length compression. Seidl et al. (2012) improved the applicability of an individual-based process based forest model aggregating light conditions among individual trees.

Here, we present results from combining a height class structure approach based on TreeMig with physiologically based equations of water use, photosynthesis and carbon allocation from LPJ-GUESS. The resulting model, TreeM-LPJ, resolves the critical problem of approximation errors introduced by combining discrete height classes with continuous growth. Given forest growth functions of gap models, organizing trees in height classes was achieved in forest landscape models (Fulton, 1991b; Löffler and Lischke, 2001; Lischke et al., 2006a). However, the aggregation here was comparatively simple because there was only one dominating feature of tree individuals (height or diameter) from which the other characteristics were derived (e.g. leaf area). In contrast, individuals in hybrid models such as LPJ-GUESS contain more state variables that describe the vegetation, including height, but also state variables that strongly influence plant carbon uptake: sapwood (which is proportional to leaf area) and fine root mass (which influences carbon allocation to leaves). In aggregating individual trees to height classes, these feedbacks between allometric properties and carbon uptake could lead to severe approximation errors.

We introduce an approach to reconcile these problems, and illustrate how the results of TreeM-LPJ using single simulations per patch are equivalent to the original hybrid model LPJ-GUESS.

\section{Material and methods}

\subsection{Source models}

Our primary aim in this study was to develop a model that can reproduce LPJ-GUESS results in an efficient and significantly faster way. To this aim, we combined the stand demographics representation of TreeMig with the physiological and biogeochemical representation of LPJ-GUESS.

The forest landscape model TreeMig (Lischke et al., 2006b) simulates forest dynamics at the species level on an annual time step and has mainly been applied at local to national scale $\left(10^{\circ}-\right.$ $10^{5} \mathrm{~km}^{2}$ ). In TreeMig, vegetation growth, mortality and seed dispersal are based on empirical relationships. The main characteristics of TreeMig are a vertical discretization of vegetation into height classes and the modeling of height specific light class distributions that produce a horizontal variability (Lischke et al., 1998; Löffler and Lischke, 2001). TreeMig is also remarkable for its representation of seed dispersal and plant migration (Lischke and Löffler, 2006), which allows the model to simulate realistic rates of change in species composition as a result of climate change (Epstein et al., 2007). A disadvantage of TreeMig is that empirical relationships are used for population dynamical processes and their environmental dependencies instead of explicitly simulating plant physiology and biogeochemical cycling. Hence, TreeMig may decline in performance under novel environmental conditions, e.g., the context of changing climate and atmospheric $\mathrm{CO}_{2}$ concentrations.
LPJ-GUESS is a process-oriented hybrid model of vegetation dynamics (Smith et al., 2001; Hickler et al., 2004). It shares characteristics with the LPJ-DGVM (Sitch et al., 2003) and the gap model GUESS (Smith et al., 2001). Plants are simulated as either functional types or species (e.g., Hickler et al., 2012). LPJ-GUESS contains a mechanistic representation of plant physiology and biogeochemical cycling including carbon assimilation, respiration, allocation and hydrology (Fig. C.1). Climatic drivers are daily temperature, precipitation and radiation or cloud coverage. One advantage of LPJ-GUESS is its mechanistic representation of plant ecophysiology, which means that it can be used under novel conditions of climate or atmospheric $\mathrm{CO}_{2}$. On the other hand, LPJ-GUESS simulations with large numbers of replicate patches are computationally demanding. Thus, to allow large scale simulations typically the amount of cohorts to simulate is reduced (e.g. by introducing establishment intervals) or the number of replicate patches is kept small (e.g. 25 in Hickler et al., 2012).

\subsection{General design of the new model}

As in TreeMig, the representation of vertical structure in TreeMLPJ is the result of discretizing the modeled forest into height classes. We used 16 predefined, static height classes with fixed upper and lower bounds. The height of the lowest height class is 2 $\mathrm{m}$; each of the higher classes has a "thickness" of $4 \mathrm{~m}$, i.e., the height classes are centered on 4, 8,12,16, ., $60 \mathrm{~m}$. Representative individuals (RIs) with fixed heights and diameters for each height class and each species characterize the vegetation of a stand. According to LPJ-GUESS, we chose to use a patch size of $833 \mathrm{~m}^{2}$ (1/ 12 ha) to simulate forest dynamics representative for whole stands. In LPJ-GUESS a horizontal variability is given by modeling the vegetation for replicate patches. With our approach only one representation per patch is simulated. The effect of the demographic (i.e. not disturbance driven) stochasticity that produces a horizontal variability is modeled only partially and indirectly by applying the new height class based approach. We adopted the tree allometry and carbon allocation to leaves, roots, heartwood, and sapwood from LPJ-GUESS. One main feature in this context is the pipe model defining a species-specific constant ratio between leaf area and sapwood cross-sectional area (Shinozaki et al., 1964). Furthermore, we included water stress functions according to LPJGUESS (stomata regulation and leaf-to-root ratio of carbon allocation). Carbon uptake, allocation, and biogeochemistry for each RI is simulated using the LPJ-GUESS equations, and the vegetation state variables (Table 1 ) are updated annually, followed by an adjustment of the biomass in each height class to account for tree height growth. The major challenge in generalizing LPJ-GUESS with the height class structure from TreeMig was the need to develop a new method for approximating the way in which biomass is transferred between the height classes as trees grow in height.

\section{Table 1}

Main state variables. TreeM-LPJ: per individual in height class. LPJ-GUESS: per individual. Y: yes. $\mathrm{N}$ : no, constant values. D: derived. *: from sapwood crosssectional area (pipe model). ${ }^{* *}$ : from sapwood carbon mass and tree diameter (condition in allocation function).

\begin{tabular}{lll}
\hline State variable & TreeM-LPJ & LPJ-GUESS \\
\hline Sap-wood carbon mass & $\mathrm{Y}$ & $\mathrm{Y}$ \\
Leaf-wood carbon mass & $\mathrm{D}^{*}$ & $\mathrm{D}^{*}$ \\
Heart-wood carbon mass & $\mathrm{D}^{* *}$ & $\mathrm{D}^{* *}$ \\
Root-wood carbon mass & $\mathrm{Y}$ & $\mathrm{Y}$ \\
Tree height and diameter & $\mathrm{N}$ & $\mathrm{Y}$ \\
Tree age & $\mathrm{Y}$ & $\mathrm{Y}$ \\
Number of individuals & $\mathrm{Y}$ & $\mathrm{Y}$ \\
\hline
\end{tabular}




\subsection{Main model functions}

\subsubsection{Carbon uptake and net primary production}

We used the LPJ-GUESS photosynthesis equations originally developed for BIOME3 (Haxeltine and Prentice, 1996b). Canopy light interception was calculated with the LPJ-GUESS fraction of photosynthetic active radiation (FPAR) function, where height classes are used to separate the foliage of trees vertically and to distribute light to tree heights according to the Lambert-Beer law (Prentice et al., 1993; Monsi and Saeki, 1953). Thus, competition for light in TreeM-LPJ works according to LPJ-GUESS functions. For each RI, we used the LPJ-GUESS net primary production (NPP) function that combines gross photosynthesis with autotrophic respiration to calculate the annually produced amount of net carbon.

\subsubsection{Growth}

As in LPJ-GUESS, at the end of each simulation year growth of tree individuals in TreeM-LPJ is a result of allocating NPP carbon to the different tree compartments (leaves, fine roots, heartwood, and sapwood), thereby increasing diameter and height. In contrast to LPJ-GUESS, these NPP and allocation triggered changes in height are not applied to the individuals directly, but serve to update the height class specific state variables (Table 1 ) in a second step by applying an extrapolation to upper height classes. Using this extrapolation, we efficiently create vertical heterogeneity without applying replicate patches, but at the cost of not updating carbon pools dynamically or considering for direct conservation of carbon mass. The goal of our growth approximation is to distribute trees over height, so that the heterogeneity created by demographic stochasticity is mimicked, and that the carbon mass in the long run develops similarly to the stochastic LPJ-GUESS carbon mass.

As in TreeMig, the number of growing individuals in a height class is modeled by transferring some individuals to upper height classes based on growth success. Applying the LPJ-GUESS growth functions to RIs leads to trees that typically have different heights from that prescribed for the RI trees in the designated height classes. These trees are named "virtual individuals" (VIs) and contain the key information to update state variables. If the height difference between an RI and a VI (equals LPJ-GUESS annual growth) is smaller than the thickness of a height class a number of

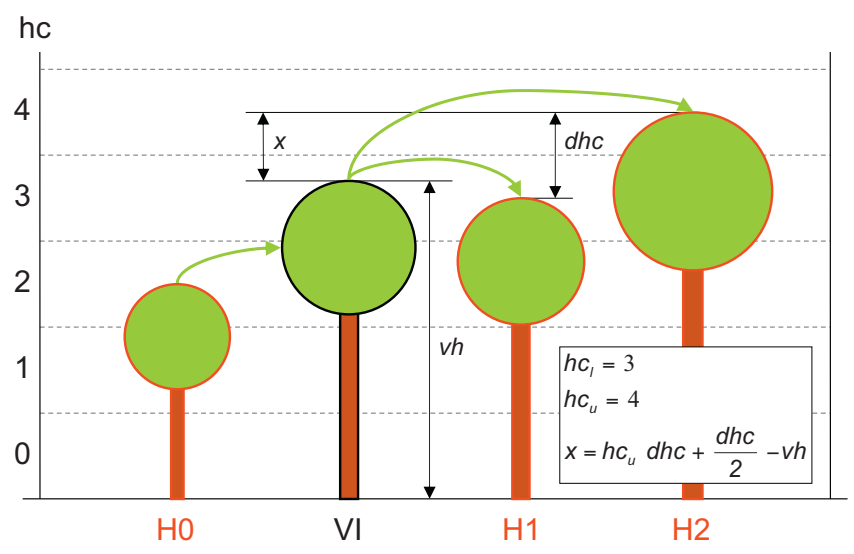

Fig. 1. Derivation of the number of growing individuals at the end of a simulation year. $h c$ : height class. H0-H2: representative individuals of height classes 2-4. VI: virtual individual. dhc: height class length. $x$ : difference between length of $\mathrm{H} 2$ and length of VI. Growth of HO first leads to VI. VI is an intermediate step to calculate changes in $\mathrm{H} 1$ and $\mathrm{H} 2$. In this example, the height difference between $\mathrm{VI}$ and $\mathrm{HO}$ is larger than dhc. Thus, all the individuals $\mathrm{H} 0$ stood for will be put either in $\mathrm{H} 1 \mathrm{or} \mathrm{H} 2$ (correspond to $h c_{l}$ and $h c_{u}$ ). The lower the ratio of $x$ to dhc is, the more individuals will be put in $\mathrm{H} 2$, and the less in $\mathrm{H} 1$. If the height difference between VI and $\mathrm{HO}$ is smaller than $d h c$, some individuals $\mathrm{H} 0$ represent will be put in $\mathrm{H} 1$ and the rest will stay in $\mathrm{HO}$ according to the same linear constraints.
Table 2

Variables and parameters appearing in the equations.

\begin{tabular}{|c|c|c|}
\hline Variable/parameter & Unit & Description \\
\hline$h$ & $\mathrm{~m}$ & $\begin{array}{l}\text { Height of representative individual in } \\
\text { height class (constant) }\end{array}$ \\
\hline$v h$ & $\mathrm{~m}$ & $\begin{array}{l}\text { Height of representative individual } \\
\text { following allocation }\end{array}$ \\
\hline$h c$ & & Height class in which trees grow \\
\hline dhc & $\mathrm{m}$ & Length of height class (constant) \\
\hline diam & $\mathrm{m}$ & Diameter of height class (constant) \\
\hline vdiam & $\mathrm{m}$ & $\begin{array}{l}\text { Diameter of representative individual } \\
\text { following allocation }\end{array}$ \\
\hline nhtcl & & Number of trees in height class \\
\hline$n$ & & Number of trees \\
\hline$A_{s}$ & $\mathrm{~m}^{2}$ & Sap-wood cross-sectional area \\
\hline$v A_{s}$ & $\mathrm{~m}^{2}$ & $\begin{array}{l}\text { Sap-wood cross-sectional area } \\
\text { following allocation }\end{array}$ \\
\hline$V_{\text {inc }}$ & $\mathrm{m}^{3}$ & Volume increment \\
\hline$\rho_{\text {wood }}$ & $\mathrm{kg} \mathrm{m}^{-3}$ & Wood density \\
\hline$m_{c_{\text {leaf }}}$ & $\mathrm{kg}$ & Leaf mass \\
\hline$m_{c_{S}}$ & $\mathrm{~kg}$ & Sap-wood mass \\
\hline$v m_{c_{s}}$ & $\mathrm{~kg}$ & Sap-wood mass following allocation \\
\hline$m_{c_{\text {root }}}$ & $\mathrm{kg}$ & Fine root mass \\
\hline$m_{c_{\text {heart }}}$ & $\mathrm{kg}$ & Heart-wood mass \\
\hline$l$ & & Subscript for lower height class \\
\hline$u$ & & Subscript for upper height class \\
\hline$n$ & & Subscript for new height class \\
\hline$h$ & & Subscript for heartwood \\
\hline$s$ & & Subscript for sapwood \\
\hline in & & Subscript for ingrowing \\
\hline SLA & & Specific leaf area (species-specific) \\
\hline LTOR & & $\begin{array}{l}\text { Leaf-to-root carbon mass ratio } \\
\text { (water stress-dependent) }\end{array}$ \\
\hline$K L$ & & $\begin{array}{l}\text { Leaf-to-sapwood area ratio (species- } \\
\text { specific) }\end{array}$ \\
\hline$S T$ & & $\begin{array}{l}\text { Species-specific sapwood mass } \\
\text { turnover ratio }\end{array}$ \\
\hline$K 2, K 3$ & & Constants in allometry equation \\
\hline
\end{tabular}

trees grow into the next height class and the rest stay in the original height class. If the annual growth exceeds the thickness of the height class, all individuals are, in accordance with TreeMig, moved to two new upper height classes (Fig. 1). We assume that all individuals that are represented by a particular RI are uniformly distributed within a height class and shift uniformly upwards with growth. Consequently, the determination of these upper height classes (the symbols are listed in Table 2) is:

$h c_{l}=\left(\frac{v h-d h c / 2}{d h c}\right) ; \quad h c_{u}=\left(\frac{v h+d h c / 2}{d h c}\right)$

and the number of trees that grow into these height classes is given by:

$n_{l, i n}=\operatorname{nhtcl} \frac{h c_{u} d h c+d h c / 2-v h}{d h c} ; \quad n_{u, i n}=n h t c l-n_{l, i n}$

depending on the thickness of the height class, and the new height ( $v h$, virtual height) an RI would reach following LPJ-GUESS allocation and allometry functions. The RI of a species in a height class always has the same prescribed height:

$h_{l}=h c_{l} d h c-\frac{d h c}{2} ; \quad h_{u}=h c_{u} d h c-\frac{d h c}{2}$

and the species-specific diameter:

$\operatorname{diam}_{l}=\left(\frac{h_{l}}{K 2}\right)^{1 / K 3} ; \quad \operatorname{diam}_{u}=\left(\frac{h_{u}}{K 2}\right)^{1 / K 3}$ 
This relation of diameter to tree height follows from the LPJ-GUESS allometry function and is also valid for the VI:

$v$ diam $=\left(\frac{v h}{K 2}\right)^{1 / K 3}$

Besides the number of individuals per height class, the carbon mass of the different tree compartments of RIs is also changed annually. One aim is to calculate the sapwood: heartwood ratio of the updated height classes. Having calculated this ratio, the other tree compartments (fine root and leaf mass) can be calculated using the LPJ-GUESS allometry functions and a leaf-to-root ratio that, according to LPJ-GUESS functions, is dynamically calculated as a function of water stress. Similar to the change in the individual density, changes in sapwood and heartwood are based on the state of the VI following LPJ-GUESS NPP, allocation and allometry functions. The basic assumption to calculate these changes is an extrapolation of the VI's state variables to the next upper RI, whereby the sapwood and heartwood will change as if the individual grew until it reached the spatial dimensions of the next RI. During this extrapolation, for each iteration step, tree diameter increments are recalculated, and sapwood mass is transferred to heartwood. This turnover depends on the mass of sapwood, which is also changed by height, making it difficult to find an analytic equation to extrapolate the VI to the next RI. Instead, we use a numerical approach (Fig. 2 and Table 3). As a basis for calculating the diameter increment of each iteration step we used a linear relationship between sapwood cross-sectional area $\left(A_{s}\right)$ and its associated volume increment $\left(V_{\text {inc }}\right)$ :

$\frac{A_{s 1}}{V_{\text {inc } 1}}=\frac{A_{s 2}}{V_{\text {inc } 2}}$

In the first iteration step, $A_{s 1}$ is the sapwood cross-sectional area of the growing RI and $A_{s 2}$ that of the associated VI. $V_{\text {inc } 1}$ is the difference in volume between the previous and the new stage (between the RI and the VI in the first iteration step):

$V_{\text {inc } 1}=h_{2} \frac{\pi}{4} \operatorname{diam}_{2}^{2}-h_{1} \frac{\pi}{4} \operatorname{diam}_{1}^{2}$

$V_{\text {inc2 }}$ is the unknown next volume increment, which contains the information for the diameter increment:

$V_{\text {inc } 2}=\left(h_{2}+h_{\text {inc2 }}\right) \frac{\pi}{4}\left(\operatorname{diam}_{2}+d_{\text {inc } 2}\right)^{2}-h_{2} \frac{\pi}{4} \operatorname{diam}_{2}^{2}$
Table 3

Characteristics of the individuals and intermediate steps of the numerical calculation. diam: diameter, $h$ : height, $V_{\text {heart }} / V_{s}$ : heartwood to sapwood ratio, H0: representative individual of currently growing height class. H1: new representative individual of upper height class. VI: virtual individual, individual after LPJ-GUESS growth. N1-NX: stages after numerical iterations. $X$ : number of numerical iterations needed. See Fig. 2 for a visualization of the numerical approach.

\begin{tabular}{|c|c|c|}
\hline & diam, $h$ & $V_{\text {heart }} / V_{\mathrm{s}}$ \\
\hline $\mathrm{HO}$ & known, constant & $\begin{array}{l}\text { known from } \\
\text { previous simulation } \\
\text { step }\end{array}$ \\
\hline $\mathrm{V} 1$ & \multirow{2}{*}{\multicolumn{2}{|c|}{$\begin{array}{l}\text { result of LPJ-GUESS growth } \\
\text { result of numerical approximation }\end{array}$}} \\
\hline$N 1-N X$ & & \\
\hline $\mathrm{H} 1$ & known, constant & $\begin{array}{l}\text { result of } \\
\text { interpolating values } \\
\text { of } N(X-10) \text { to } N X\end{array}$ \\
\hline
\end{tabular}

where the next height $h_{\text {inc2 }}$ is also not known, but can be calculated from the next diameter using LPJ-GUESS allometry:

$h_{\text {inc2 }}=\left(\operatorname{diam}_{2}+d_{\text {inc2 } 2}\right)^{K 3} K 2-h_{2}$

This system of equations (Eqs. (6)-(9)) can be solved to find the diameter increment for the next iteration step:

$d_{\text {inc2 }}=e^{\left(\ln \left(\left(h_{2} \operatorname{diam}_{2}^{2}\left(A_{s 1}+A_{s 2}\right)-h_{1} \operatorname{diam}_{1}^{2} A_{s 2}\right) / A_{s 1} K 2\right) /(2+K 3)\right)}-\operatorname{diam}_{2}$

in which the sapwood cross-sectional area can be expressed as:

$A_{s 2}=\operatorname{diam}_{2}^{2} \frac{\pi}{4}-\frac{m_{c_{\text {heart }} 2}}{h_{2} \rho_{\text {wood }}}$

and the new heartwood carbon mass as:

$m_{c_{\text {heart }} 2}=m_{c_{\text {heart } 1}}+m_{c_{\text {sap } 1}} S T$

Several tests showed that in the vast majority of cases the change of diameter increments within a growth approximation step does not change by more than factor of two to three (results not shown). However, especially if a tree has a small proportion of

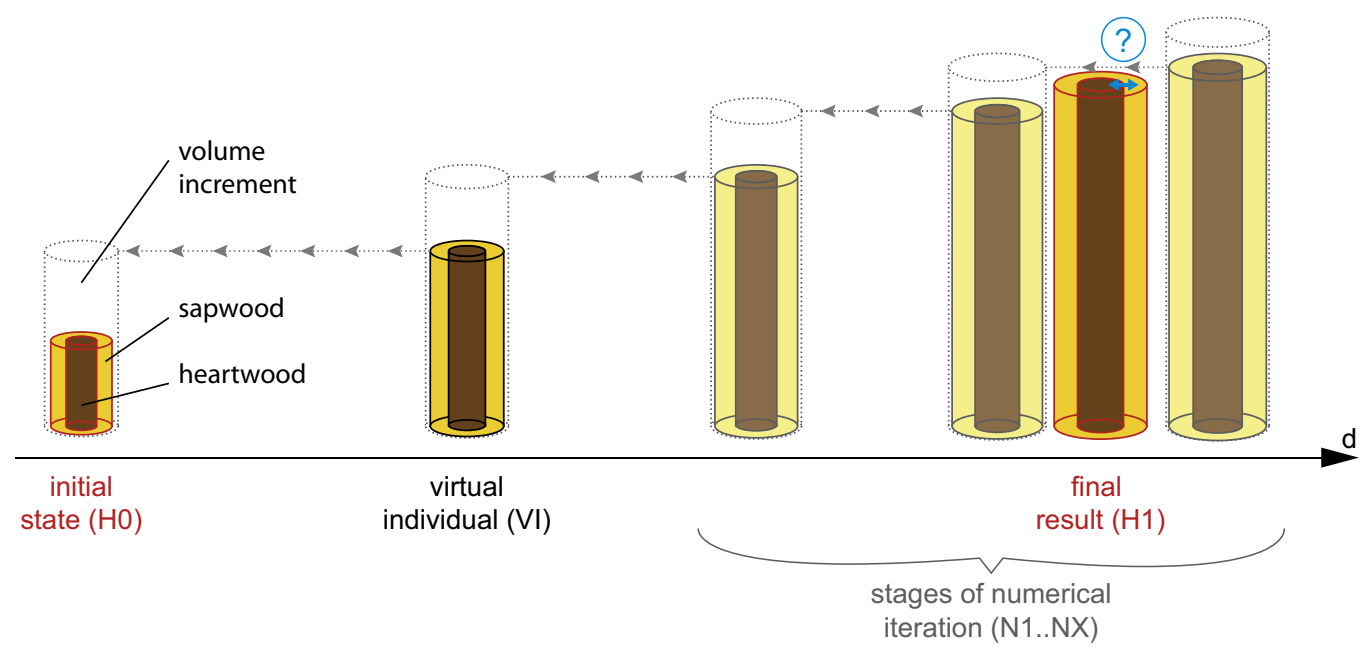

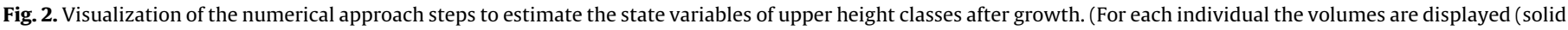

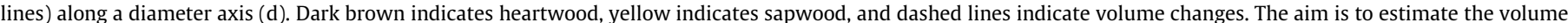

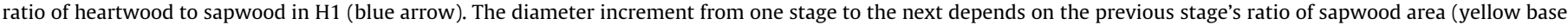
areas) to the volume increment. The proportions shown are not model results but are given to make the model clearer. See Table 3 for more details. 
sapwood cross-sectional area to basal area, and then experiences favorable growing conditions (e.g. climatic conditions, light or water availability) the growth approximation could lead to unrealistically large diameter increments (for a height class and species to have an annual diameter increment of four centimeters occurs in the numerical approximation with a probability of $10^{-4}$ per year). This results from an extrapolation of the initial LPJGUESS calculations, which already lead to large biomass increments under certain specific, unusual situations. To avoid these unrealistically large diameter increments, the increments in the numerical iteration can be four centimeters at maximum. Similarly, also poor environmental conditions can lead to unrealistically small diameter increments during the extrapolation to the next height class. Therefore, diameter increments during the numerical approximation may not fall below $10^{-4} \mathrm{~cm}$. To reach the exact dimensions of an RI, we interpolate the ten results with the nearest diameters using a 9th-order polynomial interpolation. Preliminary tests showed that a linear interpolation between the last two numerical iteration steps tends to lead to rather unrealistic results (Fig. C.2 in Appendix C).

The total change in sapwood cross-sectional area enabled us to calculate the new sap- and heartwood carbon mass:

$m_{c_{s, n, i n}}=h_{n} A_{s} \rho_{\text {wood }}$

$m_{c_{\text {heart }, n, n}}=h_{n} \frac{\pi}{4} \operatorname{diam}_{n}^{2} \rho_{\text {wood }}-m_{c_{s, n, i n}}$

Following the pipe model (Shinozaki et al., 1964) and using species-specific leaf area values, the cross-sectional area provides information about leaf mass:

$m_{c_{\text {leaf }, n, i n}}=A_{s, n} \frac{K L}{S L A}$

With the LPJ-GUESS leaf-to-root mass ratio based on water stress conditions, the root mass can be determined as follows:

$m_{c_{\text {root }, n, i n}}=\frac{m_{c_{\text {leaf }, n, i n}}}{L T O R}$

These state variables of the new RI that enters the height class are then averaged with the state variables of the RI that is already present in that class. Only individuals growing into the height class can force a growth-related change in the RI. Virtual individuals growing up and out of a lower height class do not change the state variables of the height class they are leaving. If the environmental conditions are very bad, i.e. there is no growth in 1 year, the remaining RIs undergo changes in the form of sapwood turnover.

We had to overcome one additional limitation of our method. As presented, a certain number of growing individuals of the highest occupied height class always grow into upper height classes. Hence, after fifteen simulation years, the first individuals would have already reached at least the fifteenth height class. A similar overshooting related to a height class approximation was detected by Lischke et al. (1998). To avoid such an effect, we implemented a simple "brake function" that reduces early successional growth. This function only takes effect at the tallest height class of each species that is currently occupied. It has the effect that individuals are only allowed to grow after a certain waiting period. In each year of this waiting period, the potential growth gain is accumulated. When the accumulated potential height growth is larger than the thickness of the height class, trees of that species are allowed to grow again.

\subsubsection{Mortality}

In TreeM-LPJ, the mortality function reduces individual density by decreasing the number of trees that each RI stands for. This

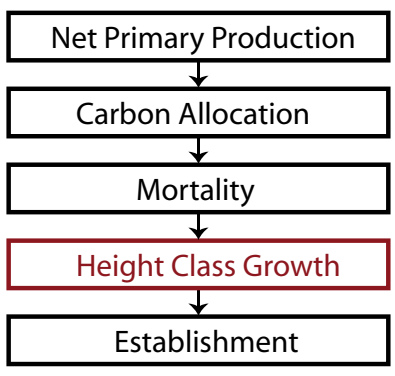

Fig. 3. Sequence of key functions called in the model. Black: functions called by LPJGUESS and TreeM-LPJ. Red: function only called by TreeM-LPJ.

function follows the same mechanism that LPJ-GUESS uses for cohorts, where growth efficiency and background mortality control the mortality rate. Growth efficiency depends on the ratio of NPP to leaf area, and background mortality depends on the age of the trees. Because TreeM-LPJ cannot explicitly track tree age with its height class method, we estimate a "virtual" tree age along with updates to the other state variables during the numerical growth approximation calculation. Here, each iteration of the growth approximation function increases the virtual tree age by 1 year. Hence, the virtual age of the RI of a height class is a function of the previous growth process, and the number of numerical iterations of the growth function. In contrast to LPJGUESS, the mortality function in TreeM-LPJ first reduces the number of trees and then the remaining trees grow (Figs. 3 and C.1 in Appendix C).

\subsubsection{Establishment}

TreeM-LPJ uses the establishment function from LPJ-GUESS, including water stress dependency. In TreeM-LPJ, tree saplings are born into the lowest height class. This height class differs from other height classes not only because it is smaller (see Section 2.2), but also because it is not represented by a tree with constant dimensions (RI). Instead, newly establishing trees mix with preexisting individuals of that tree species, leading to different state variable values. For this first model version, we do not use an establishment that depends on a propagule pool (LPJ-GUESS spatial mass effect), but use the LPJ-GUESS background establishment, which allows species to establish under favorable climate conditions. Neither the mortality nor the establishment function use stochastic terms. The growth functions used in TreeM-LPJ already lead to distributed heights.

\subsubsection{Hydrology}

We adopted the daily hydrology routines of LPJ-GUESS to model soil water, evaporation, interception and transpiration (Haxeltine and Prentice, 1996a), as well as snow and water percolation, (Gerten et al., 2004), and water stress (Haxeltine and Prentice, 1996b; Hickler et al., 2009). As in LPJ-GUESS, the ratio of transpirational demand to plant water supply and a species specific drought tolerance parameter are responsible for water stress. The drought tolerance parameter influences the establishment and the plant water supply. If the transpirational demand is greater than the plant water supply the actual transpiration equals the demand. Then, stomatal openings decrease and carbon assimilation is reduced (Haxeltine and Prentice, 1996a). Moreover, a carbon allocation to roots and a reduction in leaf growth are induced, which most probably leads to a decline in carbon assimilation in following years. These limitations in growth increase mortality rates, so that tree mortality indirectly is also a consequence of water stress. According to Gerten et al. (2004) we 
use a two-layered bucket model to model soil water. Trees distribute their fine roots to these layers with a predefined species specific ratio. We did not included lateral flows. We also did not account for the influence of soil nutrients.

\subsection{Model application and evaluation}

To test and evaluate the performance of the new TreeM-LPJ model, we performed a series of experiments in stands of different vegetation zones of the Swiss Alps. In particular, we wanted to be sure that the new model would be able to model vegetation under various climate conditions, especially those where water limitations are expected to have an important influence on the vegetation. The model simulations we performed in this study were designed to evaluate the performance, both computational and in terms of model accuracy, of our new hybrid modeling approach. As such, we apply different model set-ups in a standardized test.

\subsubsection{Location and climate data}

Our study area is in part of the Rhone valley in the Swiss canton of Valais. The bottom of this valley is one of the driest regions in Switzerland, and the hillsides form steep gradients so that environmental conditions change over short distances, and temperature and precipitation vary considerably. We selected eight stands along a north facing transect (Fig. 4, Table 4) that cover all of the major forested vegetation zones of the central Swiss Alps. The altitudinal difference between each stand is approximately $200 \mathrm{~m}$. Climate data for each stand were extracted from the CRU TS 1.2 gridded climatology (Mitchell et al., 2004) and downscaled to $100 \mathrm{~m}$ resolution using the Change Factor Method (Wilby et al., 2004). Because we were not primarily interested here in the effects of climate change, we applied the year 2000 climate data to each simulation year. The year 2000 was not an exceptional year with respect to the climate of the 20th century. Based on the Soil Suitability Map of Switzerland (Frei, 1976), we chose to use a low value for usable volumetric soil-water holding capacity of $10 \%$, and a value for soil thermal diffusivity of $0.8 \mathrm{~mm}^{2} \mathrm{~s}^{-1}$ at $15 \%$ waterholding capacity. These values correspond to the poorly developed soils on the hillsides of the Rhone valley.
Table 4

Specific characteristics of stands a-h. Lat: latitude in Swiss coordinates ( $\mathrm{CH} 1903$ / lv03 projection, longitude is $638,300 \mathrm{~m}$ for all stands). Alt: altitude above sea level. Temp: mean annual temperature. Prec: sum of precipitation during main growing period (April-September).

\begin{tabular}{lllll}
\hline Stand & Lat & Alt & Temp & Prec \\
\hline a & $127,400 \mathrm{~m}$ & $795 \mathrm{~m}$ & $9.5^{\circ} \mathrm{C}$ & $385 \mathrm{~mm}$ \\
b & $127,100 \mathrm{~m}$ & $1003 \mathrm{~m}$ & $8.5^{\circ} \mathrm{C}$ & $436 \mathrm{~mm}$ \\
c & $126,800 \mathrm{~m}$ & $1214 \mathrm{~m}$ & $7.3^{\circ} \mathrm{C}$ & $486 \mathrm{~mm}$ \\
d & $126,500 \mathrm{~m}$ & $1415 \mathrm{~m}$ & $6.2^{\circ} \mathrm{C}$ & $535 \mathrm{~mm}$ \\
e & $126,200 \mathrm{~m}$ & $1588 \mathrm{~m}$ & $5.3^{\circ} \mathrm{C}$ & $576 \mathrm{~mm}$ \\
f & $125,900 \mathrm{~m}$ & $1793 \mathrm{~m}$ & $4.3^{\circ} \mathrm{C}$ & $624 \mathrm{~mm}$ \\
g & $125,500 \mathrm{~m}$ & $1990 \mathrm{~m}$ & $3.2^{\circ} \mathrm{C}$ & $670 \mathrm{~mm}$ \\
h & $124,800 \mathrm{~m}$ & $2190 \mathrm{~m}$ & $2.1^{\circ} \mathrm{C}$ & $719 \mathrm{~mm}$ \\
\hline
\end{tabular}

\subsubsection{Tree species parameterization}

The tree species parameters we used were generally based on the existing LPJ-GUESS parameterizations for plant functional types (Hickler et al., 2004; Wolf et al., 2008) and for species (Koca et al., 2006; Miller et al., 2008; Hickler et al., 2012), and further from an unpublished LPJ-GUESS working version from mid 2008. As our aim was to compare the results of two models, we did not calibrate either model in detail. We used the most abundant Swiss forest species, selected according to the species used in TreeMig (Lischke et al., 2006a), and then analyzed which of them already had appeared in LPJ-GUESS. We excluded all other LPJ-GUESS species, but instead added three additional species that also occur in TreeMig: Larix decidua, Pinus cembra and Pinus montana. These species are abundant in the subalpine vegetation zone of the Alps, and thus had to be included in our model. Parameterization of these species was based on that used for species already parameterized for LPJ-GUESS, on comparisons with TreeMig parameters, and on expert knowledge. In contrast to most existing LPJ-GUESS parameterizations, we excluded a maximum temperature limit for Pinus sylvestris so that it could occur in warmer valley regions than might have been expected (Table C.3 in Appendix C). For Fagus sylvatica, we used a higher value of the minimum soil water content needed for establishment than for the other species to eliminate its establishment at the lower altitudes. The

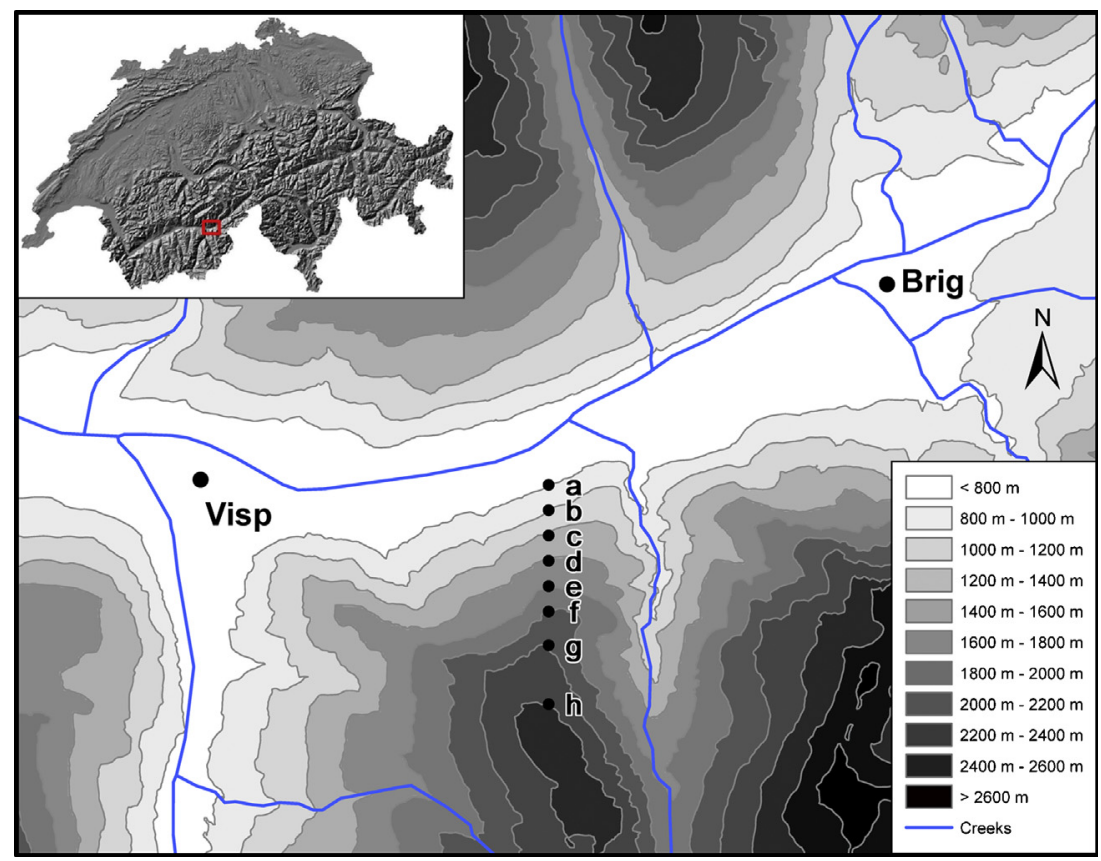

Fig. 4. Locations of the modeled stands $\mathrm{a}-\mathrm{h}$ and the surrounding terrain. 
parameters for all species differing from those of Hickler et al. (2004) are summarized in Tables C.1-C.3 (Appendix C).

\subsubsection{Model evaluation}

We evaluated both the accuracy and performance of TreeM-LPJ relative to the benchmark model LPJ-GUESS. For model accuracy, we compared the carbon stock, species composition, and height structure simulated by the two models. For model performance, we compared the time required by TreeM-LPJ to simulate vegetation at one site relative to the time LPJ-GUESS took to perform the same simulation. We ran the models for 800 years on each of the eight stands, starting from bare ground in every case. For this first comparison, the forest simulations only took into consideration plant physiological traits, and not forest disturbances and management.

To analyze whether TreeM-LPJ produces results similar to LPJGUESS, we mapped species composition, forest carbon stocks, and height structure in each of the $4 \mathrm{~m}$ thick TreeM-LPJ height classes. For TreeM-LPJ, we used the modeled height classes, and for LPJGUESS we classified the model results into height classes. We used three time points of simulation for the mapping: 30 years, 200 years and at the end of 800 years. Furthermore, to quantify the quality of the results, we calculated a root mean square error (RMSE) scaled to a range of values between 0 and 1 in four ways (see Appendix B for more details). With simulation results of a 10year resolution, we calculated either the RMSE from the sums of a 50 -year period (i.e. with five data points) around each time step to
Table 5

Total carbon mass for stands a-h after 30, 200 and 800 years of simulation time. Values in $\mathrm{kg} \mathrm{m}^{-2}$.

\begin{tabular}{|c|c|c|c|c|c|c|}
\hline \multirow[t]{2}{*}{ Stand } & \multicolumn{2}{|c|}{30 years } & \multicolumn{2}{|c|}{200 years } & \multicolumn{2}{|c|}{800 years } \\
\hline & TLPJ & LPJG & TLPJ & LPJG & TLPJ & LPJG \\
\hline $\mathrm{a}$ & 5.56 & 7.15 & 19.75 & 25.67 & 26.84 & 29.82 \\
\hline b & 5.65 & 7.17 & 19.60 & 25.01 & 21.66 & 28.95 \\
\hline c & 5.83 & 7.96 & 19.40 & 27.34 & 13.75 & 33.00 \\
\hline d & 5.77 & 7.98 & 20.80 & 31.37 & 22.92 & 32.15 \\
\hline e & 5.62 & 7.37 & 20.37 & 35.05 & 30.24 & 33.14 \\
\hline f & 5.41 & 6.81 & 20.54 & 39.10 & 31.16 & 32.07 \\
\hline $\mathrm{g}$ & 6.15 & 9.64 & 21.86 & 42.86 & 37.70 & 55.26 \\
\hline h & 6.38 & 6.94 & 33.02 & 40.85 & 38.44 & 54.01 \\
\hline
\end{tabular}

include temporal deviations (to allow small differences in time between the models), or only from the actual year difference. We applied both to the first 100 simulation years and to the whole 800 year period, resulting in four RMSE values for each species and stand. The RMSE corresponds to the differences in the species-level biomass simulated by each model.

We compared the carbon fluxes of all living individuals (gross primary production minus autotrophic respiration) of both models by tracking the annually simulated values. To analyze the potential of the TreeM-LPJ net primary production we tracked the potential

Table 6

Root mean square error (RMSE) for stands a-h. All values calculated with a temporal resolution of 10 years. I: RMSE for the total simulation of 800 years. II: RMSE for first 100 years of simulation. y: only actual year difference considered. p: period of 50 years considered. Numbers in italic indicate that in one of both models at least $2 \mathrm{kgC} \mathrm{m}^{-2}$ of that species were produced at any one point during the simulation. Bold numbers indicate values less than 0.2. (1) Larix decidua. (2) Picea abies. (3) Pinus cembra. (4) Pinus mugo. (5) Pinus sylvestris. (6) Betula pendula. (7) Carpinus betulus. (8) Coryllus avelanna. (9) Fagus sylvatica. (10) Fraxinus excelsior. (11) Quercus robur. (12) Quercus pubescens. (13) Tilia cordata.

\begin{tabular}{|c|c|c|c|c|c|c|c|c|c|c|c|c|c|c|c|}
\hline & & & 1) & 2) & 3) & 4) & 5) & 6) & 7) & 8) & 9) & 10) & 11) & 12) & 13) \\
\hline \multirow{3}{*}{ a } & I & & - & $\begin{array}{l}- \\
-\end{array}$ & - & $\begin{array}{l}- \\
-\end{array}$ & $\begin{array}{l}0.14 \\
0.13\end{array}$ & $\begin{array}{l}0.17 \\
0.17\end{array}$ & $\begin{array}{l}0.18 \\
0.17\end{array}$ & $\begin{array}{l}0.18 \\
0.12\end{array}$ & - & $\begin{array}{l}0.18 \\
0.17\end{array}$ & $\begin{array}{l}0.19 \\
0.17\end{array}$ & $\begin{array}{l}0.19 \\
0.18\end{array}$ & $\begin{array}{l}0.17 \\
0.15\end{array}$ \\
\hline & & y & - & - & - & - & 0.14 & 0.18 & 0.49 & 0.23 & - & 0.2 & 0.42 & 0.33 & 0.42 \\
\hline & II & $\begin{array}{l}y \\
\mathrm{p}\end{array}$ & - & - & - & - & 0.13 & 0.21 & 0.39 & 0.18 & - & 0.16 & 0.3 & 0.24 & 0.31 \\
\hline \multirow{4}{*}{$\mathrm{b}$} & $\mathrm{I}$ & & - & - & - & - & 0.15 & 0.18 & 0.21 & 0.19 & 0.24 & 0.23 & 0.17 & - & 0.23 \\
\hline & & $\mathrm{p}$ & - & - & - & - & 0.15 & 0.15 & 0.18 & 0.09 & 0.24 & 0.21 & 0.14 & - & 0.21 \\
\hline & & $\mathrm{y}$ & - & - & - & - & 0.21 & 0.2 & 0.4 & 0.22 & 1 & 0.27 & 0.32 & - & 0.36 \\
\hline & 11 & $\mathrm{p}$ & - & - & - & - & 0.2 & 0.19 & 0.26 & 0.13 & 1 & 0.19 & 0.24 & - & 0.24 \\
\hline \multirow{4}{*}{ C } & & $\mathrm{y}$ & 0.37 & - & 0.11 & 0.18 & 0.1 & 0.27 & 0.27 & 0.22 & 0.25 & 0.32 & 0.27 & - & 0.28 \\
\hline & & & 0.3 & - & 0.11 & 0.2 & 0.09 & 0.25 & 0.21 & 0.18 & 0.24 & 0.26 & 0.23 & - & 0.22 \\
\hline & & $\mathrm{y}$ & 0.37 & - & 0.15 & 0.3 & 0.2 & 0.27 & 0.4 & 0.24 & 0.24 & 0.44 & 0.4 & - & 0.4 \\
\hline & & $\mathrm{p}$ & 0.3 & - & 0.12 & 0.28 & 0.18 & 0.26 & 0.29 & 0.2 & 0.23 & 0.33 & 0.29 & - & 0.28 \\
\hline \multirow{4}{*}{ d } & $\mathrm{I}$ & $\mathrm{y}$ & 0.35 & 0.17 & 0.2 & 0.25 & 0.21 & 0.19 & - & 0.29 & - & 0.22 & 0.25 & - & 0.21 \\
\hline & & $\mathrm{p}$ & 0.28 & 0.16 & 0.19 & 0.15 & 0.23 & 0.16 & - & 0.21 & - & 0.16 & 0.21 & - & 0.16 \\
\hline & & $\mathrm{y}$ & 0.35 & 0.3 & 0.22 & 0.25 & 0.23 & 0.23 & - & 0.29 & - & 0.32 & 0.38 & - & 0.32 \\
\hline & 11 & $\mathrm{p}$ & 0.28 & 0.28 & 0.22 & 0.15 & 0.27 & 0.2 & - & 0.21 & - & 0.21 & 0.27 & - & 0.21 \\
\hline \multirow{4}{*}{ e } & & $\mathrm{y}$ & 0.31 & 0.17 & 0.2 & 0.23 & 0.26 & 0.26 & - & 0.18 & - & - & - & - & - \\
\hline & & $\mathrm{p}$ & 0.21 & 0.17 & 0.17 & 0.13 & 0.25 & 0.19 & - & 0.13 & - & - & - & - & - \\
\hline & & $\mathrm{y}$ & 0.31 & 0.24 & 0.22 & 0.23 & 0.3 & 0.35 & - & 0.28 & - & - & - & - & - \\
\hline & & $\mathrm{p}$ & 0.21 & 0.22 & 0.2 & 0.13 & 0.31 & 0.25 & - & 0.2 & - & - & - & - & - \\
\hline \multirow{4}{*}{ f } & & $\mathrm{y}$ & 0.27 & 0.16 & 0.19 & 0.22 & 0.29 & 0.28 & - & - & - & - & - & - & - \\
\hline & & $\mathrm{p}$ & 0.23 & 0.16 & 0.15 & 0.1 & 0.3 & 0.22 & - & - & - & - & - & - & - \\
\hline & & $\mathrm{y}$ & 0.27 & 0.22 & 0.19 & 0.22 & 0.3 & 0.31 & - & - & - & - & - & - & - \\
\hline & & $\mathrm{p}$ & 0.23 & 0.2 & 0.15 & & 0.32 & 0.26 & & - & - & - & - & - & - \\
\hline \multirow{4}{*}{ g } & & $\mathrm{y}$ & 0.13 & - & 0.22 & 0.22 & 0.22 & - & - & - & - & - & - & - & - \\
\hline & & $\mathrm{p}$ & 0.16 & - & 0.21 & 0.23 & 0.22 & - & - & - & - & - & - & - & - \\
\hline & II & y & 0.24 & - & 0.23 & 0.27 & 0.32 & - & - & - & - & - & - & - & - \\
\hline & & $\mathrm{p}$ & 0.18 & - & 0.22 & 0.19 & 0.27 & - & - & - & - & - & - & - & - \\
\hline \multirow{4}{*}{$\mathrm{h}$} & & $\mathrm{y}$ & 0.07 & - & 0.16 & - & - & - & - & - & - & - & - & - & - \\
\hline & & $\mathrm{p}$ & 0.05 & - & 0.15 & - & - & - & - & - & - & - & - & - & - \\
\hline & & $\mathrm{y}$ & 0.18 & - & 0.32 & - & - & - & - & - & - & - & - & - & - \\
\hline & & $\mathrm{p}$ & 0.13 & - & 0.27 & - & - & - & 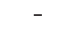 & - & - & - & - & - & - \\
\hline
\end{tabular}


carbon fluxes, which are calculated directly after the net primary production function. To analyze the realized production of TreeM-LPJ, we tracked fluxes calculated after the growth approximation. We evaluated the performance of the models by comparing the simulation times of TreeM-LPJ and LPJ-GUESS. For LPJ-GUESS, we used 100 replicate patches. Because TreeMLPJ is not a gap model, its results are an outcome of one representation. We repeated all simulations 25 times and used the mean simulation time needed to compare the model performance. The simulations ran on one core of an AMD Opteron $24392.8 \mathrm{GHz}$ processor.

\section{Results}

At all of the stands in our representative application, TreeM-LPJ reproduced the LPJ-GUESS model results with sufficient quality, and took only about 20\% of the time LPJ-GUESS needed as described below. All species listed in Tables C.1-C.3 (Appendix C) occurred in the simulations. Stand "a" was dominated by Pinus sylvestris and Quercus pubescens, stand "c" by Fagus sylvatica. Stand "b" simulations led to all the tree species that also occurred in stands "a" and "c" apart from Quercus pubescens. Stands "d" to "f" are dominated by Picea abies. More upslope, at stand "g", no Picea
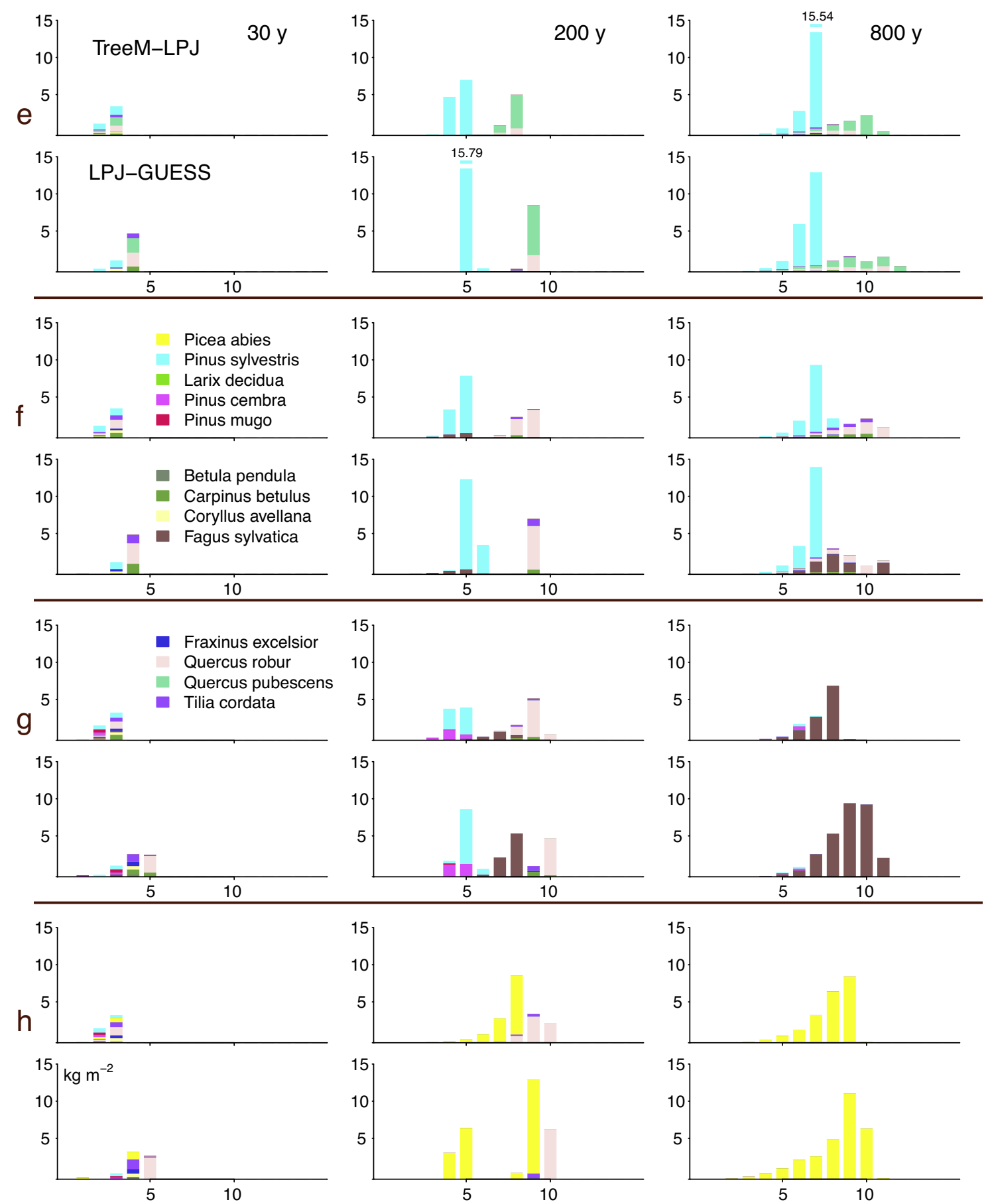

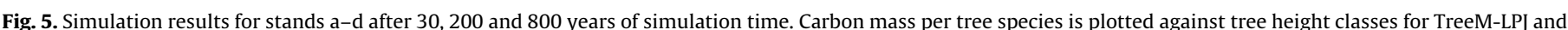

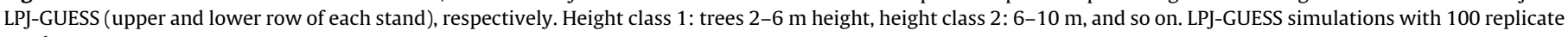
patches. 
abies grew and both Pinus sylvestris and Pinus cembra appeared again. At the most upper stand, stand "h", Pinus cembra was the only tree species that could establish during the simulation period. The total biomass estimated by the two models for some stands was similar but for others differed up to 50\%. After 200 years of simulation time, TreeM-LPJ biomass was generally lower than LPJ-GUESS biomass (Table 5). After 800 years of simulation time, TreeM-LPJ produced less biomass than LPJGUESS at stands with Fagus sylvatica and at high-altitude stands. For all stands and all simulation years, both models produced similar tree species compositions and maximum tree heights (Figs. 5 and 6). In general, trees grew a little slower in TreeM-LPJ than in LPJ-GUESS (Table 5, Figs. 5 and 6, left column). The vegetation carbon fluxes produced by LPJ-GUESS and the potential fluxes of TreeM-LPJ were similar (Fig. 7). One exception is that TreeM-LPJ has a higher potential to produce fluxes, i.e. more carbon assimilation than respiration, in the first 200 to 400 years of simulation compared to LPJ-GUESS. This was compensated for by higher fluxes from LPJ-GUESS in the later simulation years. The realized fluxes of TreeM-LPJ differ much more from the LPJ-GUESS fluxes. They alternate between values slightly higher than the LPJ-GUESS values and approximately half of LPJ-GUESS values in most analyzed stands and especially in the first half of the simulations.
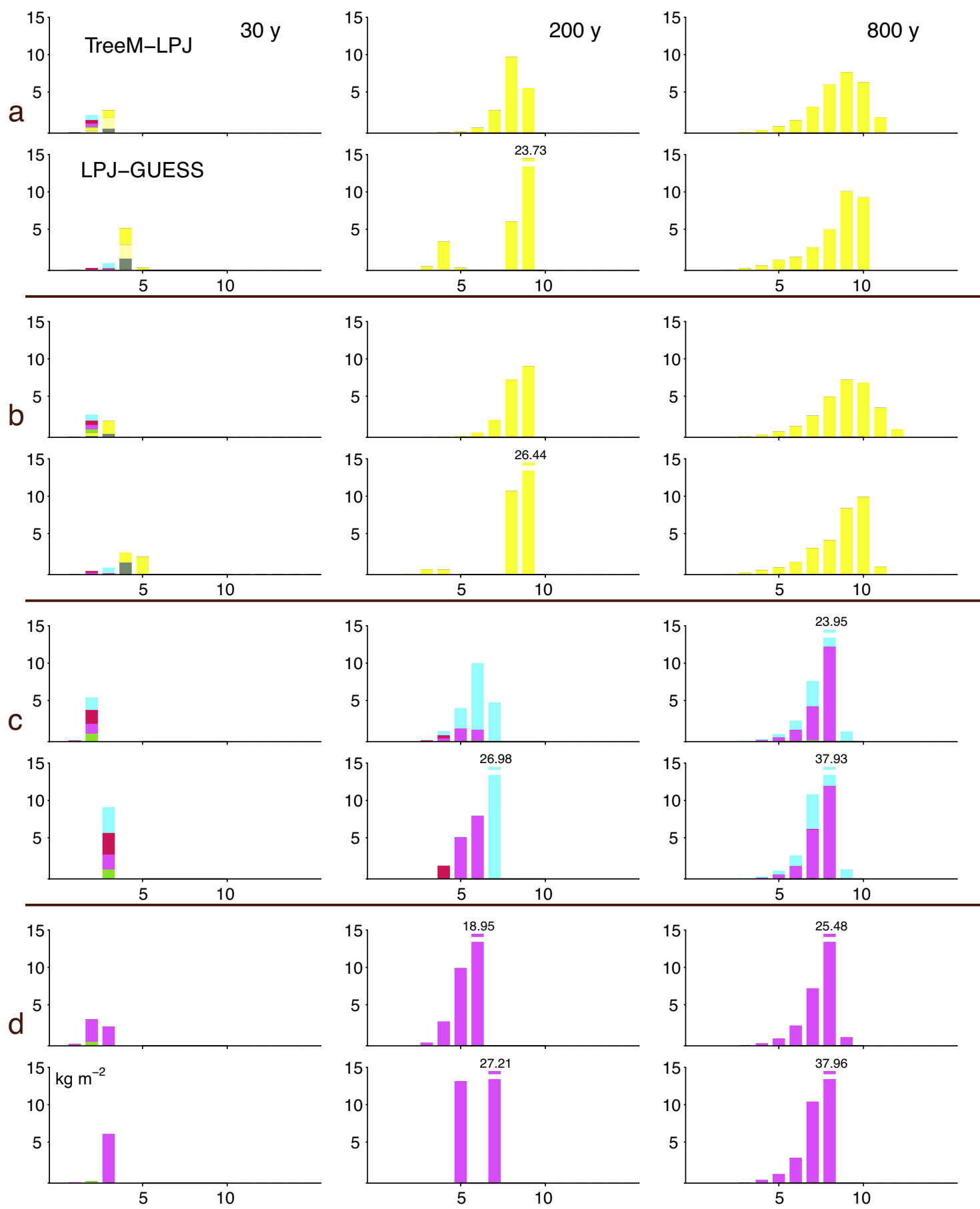

Fig. 6. Simulation results for stands e to h after 30, 200 and 800 years of simulation time. See Fig. 5 for description. 


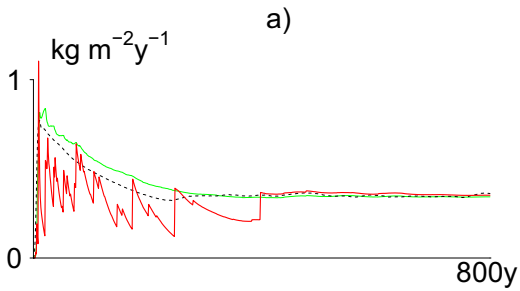

c)

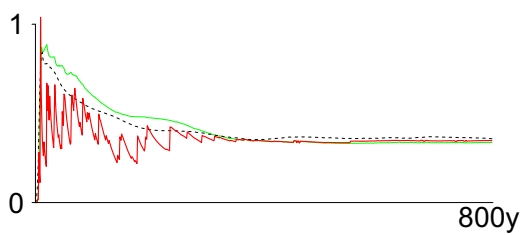

e)
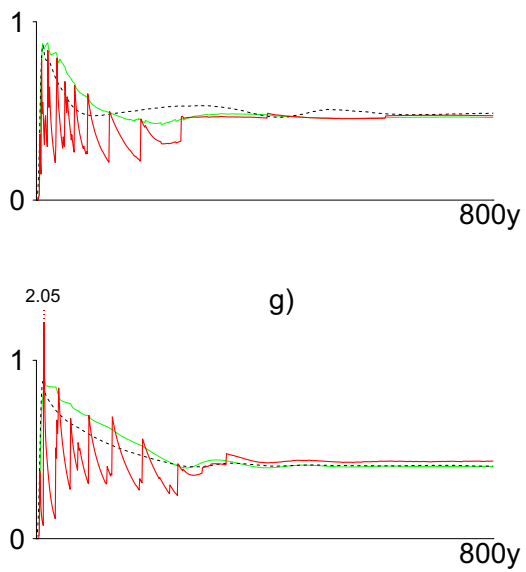

b)

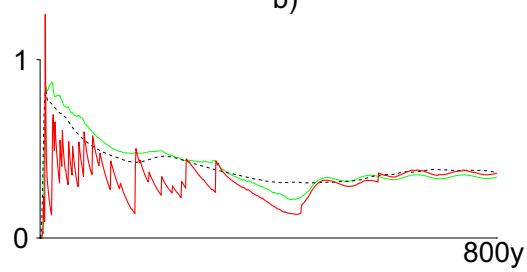

d)

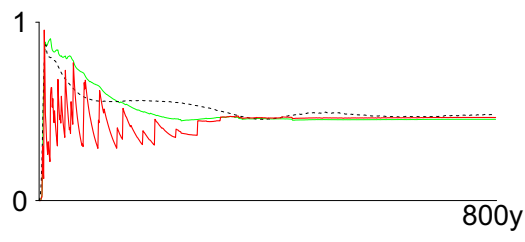

f)
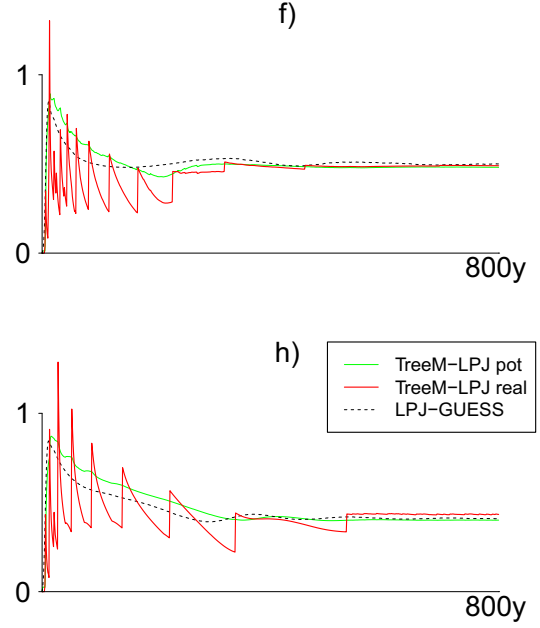

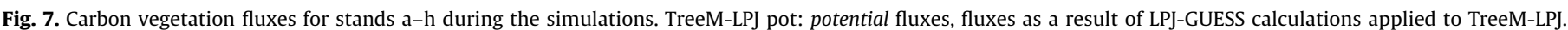

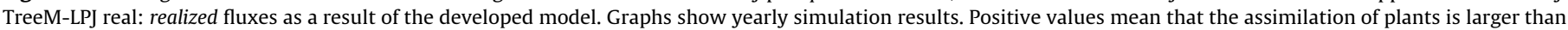

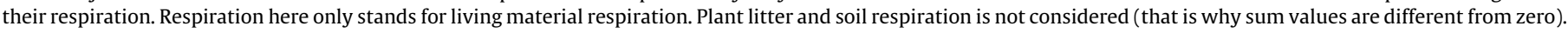
All tree species from one stand contribute to the results.

The results of the RMSE calculation indicate that the representation of the modeled species differed little in both models (Table 6). For the total of 800 years, all the RMSE values calculated fall below 0.4 , or even below 0.3 when a 50 -year averaging period was used. Calculating the RMSE for only the first 100 simulation years in most cases allowed the values to increase only if the current years were considered. They again decreased if 50-year periods were used. Generally, the dominant tree species had the lowest RMSE except at stands with Fagus sylvatica and at

Table 7

Simulation time for stands a-h. Simulation times for 800 years of simulation with TreeM-LPJ and LPJ-GUESS (both shown as means of 25 simulation runs). For LPJ-GUESS 100 replicate patches were used (standard value). Simulations were run on one core of an AMD Opteron $24392.8 \mathrm{GHz}$ processor.

\begin{tabular}{lrl}
\hline Stand & TLPJ & LPJG \\
\hline a & $107.79 \mathrm{~s}$ & $656.93 \mathrm{~s}$ \\
$\mathrm{~b}$ & $96.91 \mathrm{~s}$ & $588.02 \mathrm{~s}$ \\
$\mathrm{c}$ & $84.91 \mathrm{~s}$ & $655.63 \mathrm{~s}$ \\
$\mathrm{~d}$ & $76.80 \mathrm{~s}$ & $559.52 \mathrm{~s}$ \\
$\mathrm{e}$ & $83.20 \mathrm{~s}$ & $590.88 \mathrm{~s}$ \\
$\mathrm{f}$ & $70.33 \mathrm{~s}$ & $582.18 \mathrm{~s}$ \\
$\mathrm{~g}$ & $78.43 \mathrm{~s}$ & $787.91 \mathrm{~s}$ \\
$\mathrm{~h}$ & $69.23 \mathrm{~s}$ & $590.81 \mathrm{~s}$ \\
\hline
\end{tabular}

high altitudes. Table 7 shows how TreeM-LPJ performed in comparison to LPJ-GUESS. Simulation times for all runs were approximately five times faster with TreeM-LPJ than with LPJGUESS with 100 replicate patches.

\section{Discussion}

With its mechanistic physiological basis and new height-class approach, the TreeM-LPJ forest model red demonstrates both the challenges and opportunities present in developing a computationally efficient forest stand model. Our new methodology may serve as a basis for the further development of large-scale vegetation models. The key challenge in the development of TreeM-LPJ was finding a method to assign continuously growing individuals to discrete height classes, and then updating the associated state variables in a consistent way while at the same time minimizing discretization errors. This was particularly challenging because, in contrast to TreeMig, not only the numbers of individuals per tree height, but also the state variable of sapwood cross-sectional area, had continuously to be updated. By applying a novel method (see Section 2.3.2) for iteratively assigning biomass to height classes, we succeeded in creating a model that produced results similar to LPJ-GUESS while using only $20 \%$ of the computation time. 


\subsection{Performance of approximation}

The comparison between LPJ-GUESS and TreeM-LPJ simulations demonstrates that we succeeded in the goals of this work. The simulated biomass, height structures and species compositions at different sites and time points did not differ greatly between models. Moreover, the RMSE values of all calculations were low, and the simulation time of TreeM-LPJ was substantially shorter than LPJ-GUESS. TreeM-LPJ requires approximately $20 \%$ of the simulation time LPJ-GUESS requires using 100 replicate patches. A smaller amount of patches would decrease simulation times but not provide reliable mean output because of a higher stochastic variability. This in particular could affect the forest height class distribution. Hence, to capture demographic heterogeneity a large number of patches is necessary for LPJ-GUESS simulations, while with TreeM-LPJ, because of the newly developed growth mechanism, some biomass always remains in lower height classes, and thus leads to a distribution of individuals over height classes.

A few important discrepancies between the models remain. The applied approximation of the NPP carbon introduces a difference between the potential TreeM-LPJ fluxes and the model's realized fluxes, and also with the original LPJ-GUESS fluxes (Fig. 7). These differences are a direct consequence of the growth approximation and "brake function" we used (see Section 2.3.2). We therefore recommend caution when using this approach for carbon-flux related studies; the main potential application of the TreeM-LPJ approach will be for forest studies of forest dynamics that are constrained by realistic plant physiology. Such "climate-aware" forest modeling is becoming increasingly important for forest management in a warming world with higher atmospheric $\mathrm{CO}_{2}$ concentrations, where the traditionally used growth-and-yield table approach may not apply under very different environmental conditions (Crookston et al., 2010).

Despite the fact that the TreeM-LPJ approach introduces several important simplifications in order to increase computational efficiency, e.g., the model does not a priori conserve carbon, our methodology is nevertheless useful. The differences between NPP simulated by LPJ-GUESS and the potential NPP simulated by TreeMLPJ are very small. In this sense, the approximation errors from the applied fluxes are not additive, and in contrast, disappear in the equilibrium state of the simulations. Furthermore, and related to the carbon flux issue, trees grew a little more slowly in TreeM-LPJ compared to LPJ-GUESS at the beginning of the simulations, which was also expressed by the higher RMSE values for the first 100 years compared to the total simulation time results (Table 6, Figs. 5 and 6 , left column). When we used a 50-year averaging period for RMSE the differences between the two models over the first 100 years of the simulation were reduced, suggesting that apart from a temporal discontinuity between the models at the very beginning of the simulation, in the first century the results were in good agreement with one another. Slower growth in TreeM-LPJ is mainly due to the reduction of the overshooting effect (discussed in detail in Section 2.3.2), which results in the opposite model behavior, i.e., a suppression in the growth rate of small trees. This suppression is the reason that TreeM-LPJ has a higher potential to produce carbon fluxes in the first 200 to 400 years of simulation compared to LPJ-GUESS. Despite the used approximation, the TreeM-LPJ results for the early successional stages seem to be more realistic since, with LPJ-GUESS simulations, trees can reach heights of as much as $20 \mathrm{~m}$ or more within 30 years. While such rates might be possible under optimal conditions (Schober, 1987), they are not the rule on the rather poor soils as in the analyzed examples and harsh climate that characterize our study area. The rapid height growth rate of small trees simulated by LPJ-GUESS, however, could be also due to parameterization or the relatively simple allometric relationships used in the model.

\subsection{Growth function and height discretization}

The height discretization introduced in TreeM-LPJ required several approximations. One was the "brake function" to reduce growth in the highest occupied height class (as described in Section 2.3.2). This function had to be introduced to avoid the overshooting of biomass in early successional stages typical for height structured models such as TreeMig and its predecessor DisCForM (Lischke et al., 1998). The reason for the overshooting is that in each year a small portion of all trees enters the following height class, which means that the highest height class is reached too soon. We are aware of the fact that the "brake function" we used might lead to deviations from continuous growth. However, several tests showed that the simulated difference with continuous growth was much smaller than when using model simulations that allowed the overshooting effect (results not shown). Thus, our "brake function" reduces the errors of approximations introduced by the height class approach.

Another issue affected by the height discretization is conservation of mass. The major difficulty in modeling forests on a heightclass basis is defining how many individuals grow from one height class to the next to ensure that this growth represents the continuous case without deviations in mass and total leaf area. However, if the number of growing individuals is calculated proportionally to the height increment (as used in our approach, Eq. (2), Fig. 1) the total mass will always be greater than in the continuous case (columns L and H of Fig. C.3 in Appendix C) as long as tree biomass increases exponentially with height (as implemented in LPJ-GUESS and most common in nature). An alternative approach would be to calculate the number of growing individuals not proportionally to changes in height but rather to changes in mass, so that the total mass after distributing trees to height classes is conserved. However, this was found to be not applicable because then only few individuals grow to the upper height class (column M of Fig. C.3 in Appendix C) and the overall resulting trees have less leaf area and a smaller potential for the following year's carbon assimilation than do trees in the continuous case at the same stage. Larger trees might not only have more biomass than smaller trees, but might also have a larger leaf area, even though leaf area still increases more slowly. In contrast, our approach does not account for the direct conservation of mass but leads to trees with a total leaf area similar to the continuous case, and thus, a similar potential for carbon assimilation and shading effects (column H of Fig. C.3 in Appendix C). Hence, we deliberately focus on representing the variable that has the largest effect on the dynamics, the leaf area, calculated from sapwood area.

One characteristic of TreeM-LPJ is that only one representation of a patch that represents a whole stand is modeled. The consequence of this aggregation is that no horizontal variabilities are modeled, i.e. the new approach reflects only the vertical heterogeneity resulting from stochastic demography, not the horizontal (or patch to patch) heterogeneity determining dynamics in many gap models. For example, in the aggregation of the gap model FORCLIM to the distribution based model DisCForM the horizontal heterogeneity was crucial for representing the gap model results (Löffler and Lischke, 2001). However, the mean results produced by our simulations are similar to the LPJ-GUESS results that use 100 replicate patches, which is astonishing, and points to a minor influence of horizontal heterogeneity in LPJGUESS.

The numerical approach used to estimate the sapwood to heartwood ratio of upper height classes (Fig. 2 and Table 3) involved several challenges:

(1) To consistently adjust sapwood: heartwood in each height class, we applied an approximation scheme to the growth formulation used by LPJ-GUESS using initial conditions from the 
previous year's growth (see Section 2.3.2, Fig. 2 and Table 3) and a simple linear relationship between the sapwood cross-sectional area and volume increment. Observations corroborating this relationship have been reported for different tree species (e.g., Gilmore and Seymour, 1996; O'Hara et al., 1999; Schroeder et al., 1982 (as cited in Waring, 1985)). The principle is related to the pipe model (Shinozaki et al., 1964), where sapwood cross-sectional area is proportional to leaf area. Leaf area is a proxy for the amount of assimilated carbon and, thus, for the volume increment. This argumentation fails to take into account possible differences in carbon assimilation per leaf area for trees of different heights, e.g., as a result of light or hydraulic limitations. In spite of these simplifications, our method limits errors by applying the approximation only over short ranges of tree heights, i.e. over a maximum of a height class thickness of $4 \mathrm{~m}$ Further technical details about the numerical approach are provided in Appendix C.

(2) The numerical approach we developed requires a considerable amount of computation time to iterate to a stable solution for height increment, although this needs only to be calculated at the end of a simulation year, as revealed by tests using different stop criteria for diameter increment changes (see Appendix A). Future model optimizations should therefore focus on this part of the model. The total simulation times, however, are still $80 \%$ shorter than the LPJ-GUESS simulations using 100 replicate patches.

(3) With the approximation scheme of the full model used for extrapolating the tree dimensions to the target height, we implicitly assume that some individuals have repeated growth and mortality within 1 year. This additional growth and aging between the yearly time steps seems rather counterintuitive. However, if the growth of an RI is smaller than the height class length, some individuals of the original height class do not grow at all. This stagnation compensates for the additional growth and aging of the growing individuals.

Regarding all these challenges, the results of TreeM-LPJ are remarkably similar to those from LPJ-GUESS, at least as far as the height distributions of tree species are concerned. Hence, averaging between individuals from the different height classes does seem to work properly. Furthermore, all the problems with the numerical approach and the non-growing fraction would have less severe effects if the discretization of the height classes were made smaller. Such a discretization, however, would increase the computation time.

\subsection{Comparison to naturally occurring vegetation}

The aim of this study was not to perform a comprehensive evaluation of TreeM-LPJ but to compare it with the more complex LPJ-GUESS to ensure that the new model satisfactorily reproduces the properties of the benchmark model. Nevertheless, the simulation results do allow a first assessment of the model's applicability. Not only does TreeM-LPJ reproduce LPJ-GUESS results well, but the resulting tree species composition and distribution of both models also roughly reflect the natural species compositions occurring in the study region. These range from Pinus sylvestris-Quercus pubescens forests in the low dry valley bottom, over mixed and spruce forests on the slopes to Pinus cembra dominated subalpine forests.

There are some exceptions. (1) Fagus sylvatica does not grow on the slopes of the dry Rhone valley, but it was not possible for us to exclude it through parameterization (Fig. 5, b and c). However, this could be a result of our oversimplified experimental setup where only the climate of year 2000 was used in the spinup period. Interestingly, Fagus sylvatica is much more abundant in LPJ-GUESS than in TreeM-LPJ. This could be due to the new growth approach or to the mortality function. The comparison between our model results and observations should not be analyzed in great detail because our main concern was to compare the models. (2) There are too few pioneer species, particularly Larix decidua (Fig. 6). This deficit can partially be explained by the lack of disturbance events. But it does not explain why pioneer species occur so rarely at the beginning of the simulations. An additional parameterization could be a solution. (3) It is not reasonable for Pinus cembra to occur at relatively low altitudes, but some Pinus cembra trees could establish even below Picea Abies (Fig. 5, c).

Both models we analyzed, LPJ-GUESS and TreeM-LPJ, simulate unrealistically high total biomass compared to observations. This may be because our model simulations did not include historical disturbance, such as windthrow, fire, or timber harvest. Brändli (2009) recorded the current forest stock in Valais as approximately $262 \mathrm{~kg} \mathrm{ha}^{-1}$, corresponding to less than $7 \mathrm{kgC} \mathrm{m}^{-2}$ (assuming $250 \mathrm{kgC} \mathrm{m}^{-3}$ wood $^{-1}$ ), which is over four times less than produced by our LPJ-GUESS simulations. Although these forest inventory data might be influenced by management and forest history, it is a clear indication that our LPJ-GUESS simulations overestimate the carbon stock by far. The main reason for this is that we did not include patch replacing small scale disturbances. It is well known that LPJ-GUESS output is largely affected by disturbances (Hickler et al., 2004; Gritti et al., 2006). TreeM-LPJ could consequently be improved by integrating disturbance and management functions, but without sacrificing the gain in efficiency in modeling time.

\section{Conclusions and outlook}

In this paper we introduce TreeM-LPJ, a vegetation model that not only simulates vertical structure in a forest but also includes a complete process representation of ecophysiology, and requires less than $20 \%$ of the computation time needed for models with similar features. The growth approach of TreeM-LPJ based on height classes reveals the potential of modeling forest ecophysiology and dynamics more effectively. The model can efficiently reproduce the results of the biogeochemical model LPJ-GUESS, which uses time-consuming successive repetitions of replicate patches with tree cohorts to simulate in-stand variability. Although the new model can only be applied at the moment to undisturbed stands, this first attempt to simulate the forest biomass, species composition and height structure of stands in a process-oriented way using deterministic functions has proved successful. TreeM-LPJ's greatest limitation is the representation of small-scale disturbances. was addressed in a companion study (Scherstjanoi et al., 2013). Further developments to the model will include a grid-based modeling with seed dispersal among simulated grid cells, and additional strategies to optimize simulation performance.

The discretization and applied numerical approach used here are not restricted to the specific model TreeM-LPJ. Both could be also used for other hybrid Dynamic Global Vegetation Models based on individual tree growth, e.g. SEIB-DGVM (Sato et al., 2007). They could also be used to approximate tree growth in other forest models if a detailed simulation would be too time-consuming. It is even conceivable that, with this approach, height structure could be included in classical DGVMs, where, up to now, one PFT has only one specific but changing height.

\section{Acknowledgements}

This study is part of the project SER-C07.00123 (MEPHYSTO) funded by the Swiss COST office at the Swiss State Secretariat for Research and Education SBF and of the COST action FP0603 "Forest models for research and decision support in sustainable forest management". Jed O. Kaplan was supported by the Swiss National Science Foundation (grants PP0022_119049 and PP00P2_139193) 
and by FIRB project CASTANEA (RBID08LNFJ). We thank Thomas Wuest for IT support and Dirk Schmatz for providing the downscaled climate data.

\section{Appendix A. Technical details of the numerical approach}

As in natural forests, in the numerical growth approximation of TreeM-LPJ annual tree diameter increment typically declines as individuals get larger. But younger trees especially can also increase their diameter increments, e.g. if light or climate conditions improve, for at least a few years. Tests revealed that this effect is also captured in the approach we use (results not shown). But under certain conditions, little sapwood can produce a comparatively large sapwood increment, so that the following iteration steps can lead to an overestimation of diameter increments (positive feedback). Therefore, we set a limit to the maximum annual diameter increment of four centimeters. Furthermore, we used a minimum diameter increment of $10^{-3} \mathrm{~mm}$. This limit was necessary because trees that grow slowly might become stuck during the extrapolation to the previous height class, i.e. their diameter can fall to zero. Treating them as dead would mean wasting their potential to change individuals in the designated height class. The minimum diameter increment does not tackle the problem of the general relationship between successive years with very small diameter increment and mortality (e.g., Bigler et al., 2006). This fact is, however, already covered by the LPJ-GUESS mortality as a result of growth efficiency.

\section{Appendix B. Calculation of the root mean square error}

The differences in carbon mass of one species between the two model outputs to compare $\left(C_{m 1}, C_{m 2}\right)$ are summed up for each $y r(10$ year resolution) between $y_{\text {start }}$ (first simulation year) and $y_{\text {end }}$ (simulation year 100 or year 800 ), and for each height class ( $h t c l$ ) up to the number of height classes (nhtcl), also considering neighboring height classes (htcln) and subsequent years $\left(y r_{n}\right)$ in dependency of the size of the time window ( $t w=0$ or 50 , note that in the time window also only years are considered that can be divided by 10). These differences

$$
\begin{aligned}
c_{m d, y r, h t c l}= & \sum_{y r_{n}=\max \left(y r-t w / 2, y_{\text {start }}\right) h t c l n=\max (h t c l-1,1)}^{\min \left(y r+t w / 2, y_{\text {end }}\right)} C_{m 1, h t c l n, y r_{n}}^{\min (h t c l+1, n h t c l)} \\
& -\sum_{y r_{n}=\max \left(y r-t w / 2, y_{\text {start }}\right) h t c l n=\max (h t c l-1,1)}^{\min \left(y r+t w / 2, y_{\text {end }}\right)} C_{m 2, h t c l n, y r_{n}}^{\min (h t c l+1, n h t c l)}
\end{aligned}
$$

are scaled by the maximum carbon mass appearing in the period defined by the time window:

$c_{m m}=\max \left(\sum_{h t c l=1 h t c l n=\max (h t c l-1,1)}^{n h t c l} \sum_{y r_{n}=y_{\text {start }}}^{\min (h t c l+1, n h t c l)} C_{m 1, h t c l n, y r_{n}}\right.$,

$\sum_{h t c l=1}^{n h t c l} \sum_{y r_{n}=y_{\text {start }}}^{\min (h t c l+1, n h t c l)} C_{m 2, h t c l n, y r_{n}}$,

$\sum_{h t c l=1 h t c l n=\max (h t c l-1,1)}^{n h t c l} \sum_{r_{n}=\max \left(y_{\text {start }}+1-t w / 2, y_{\text {start }}\right)}^{\min (h t c l+1, n h t c l)} C_{m 1, h t c l n, y r_{n}}$,

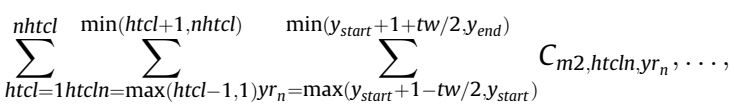

$\sum_{h t c l=1 h t c l n=\max (h t c l-1,1) y r_{n}=\max \left(y_{\text {end }}-t w / 2, y_{\text {start }}\right)}^{\text {nhtcl }} \sum_{m 1, y r_{n}}^{\min (h t c l+1, n h t c l)}$,

$\left.\sum_{h t c l=1}^{n h t c l} \sum_{h t c l n=\max (h t c l-1,1) y r_{n}=\max \left(y_{\text {end }}-t w / 2, y_{\text {start }}\right)}^{\min (h t c l+1, n h t c l)} C_{m 2, y r_{n}}\right)$ to allow only values between 0 and 1 . Then its square is summed up and divided by the number of elements to sum up (height classes times years). The root of it is the root mean square error:

$r m s e=\sqrt{\frac{\sum_{h t c l=1}^{n h t c l} \sum_{y r=y_{\text {start }}}^{y_{\text {end }}}\left(C_{m d, y r, h t c l} / C_{m m}\right)^{2}}{n h t c l\left(y_{\text {end }}-y_{\text {start }}\right) / 10}}$

\section{Appendix C}

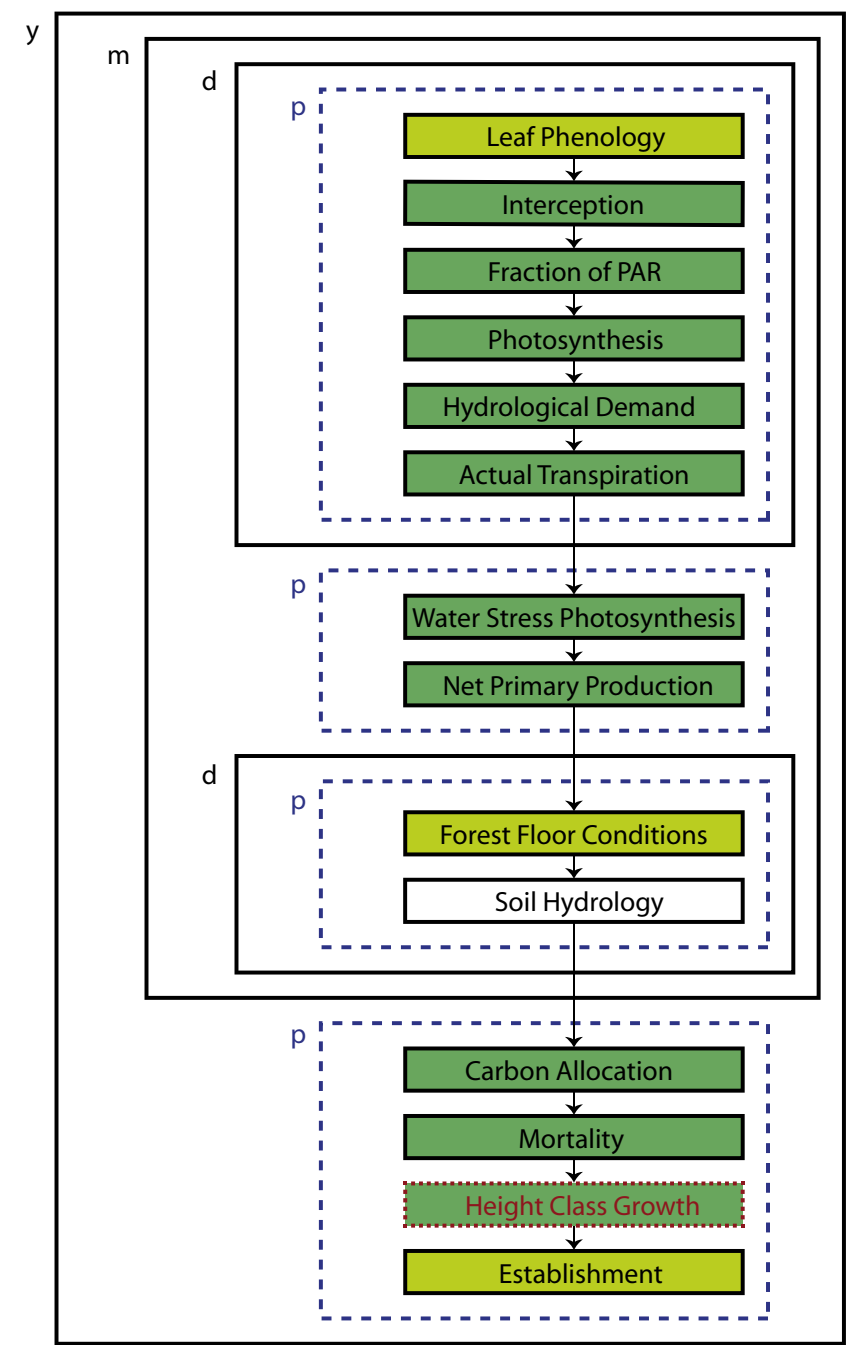

Fig. C.1. Schematic Model of TreeM-LPJ and LPJ-GUESS. Simulations cycle from top down until the number of simulation years is reached. Large rectangles stand for simulation loops. y: yearly loop. m: monthly loop. d: daily loop. p: patch loop. Light green: function called for each species. Dark green: function called for each species and cohort (LPJ-GUESS) or height class (TreeM-LPJ, if occupied). Blue, dashed: called only by LPJ-GUESS. Red, dotted: called only by TreeM-LPJ. Photosynthesis is always calculated daily with maximum stomatal aperture (no water stress). Its output is needed to calculate the hydrological demand. If in a month water stress appears, photosynthesis will be called once more, but with reduced stomatal aperture. The amount of assimilated carbon is then extrapolated to the number of water stress days this month. Photosynthesis and water stress are implemented in TreeM-LPJ according to LPJ-GUESS functions. The new functions that characterize TreeM-LPJ and that are described here are inside of the Height Class Growth box. 


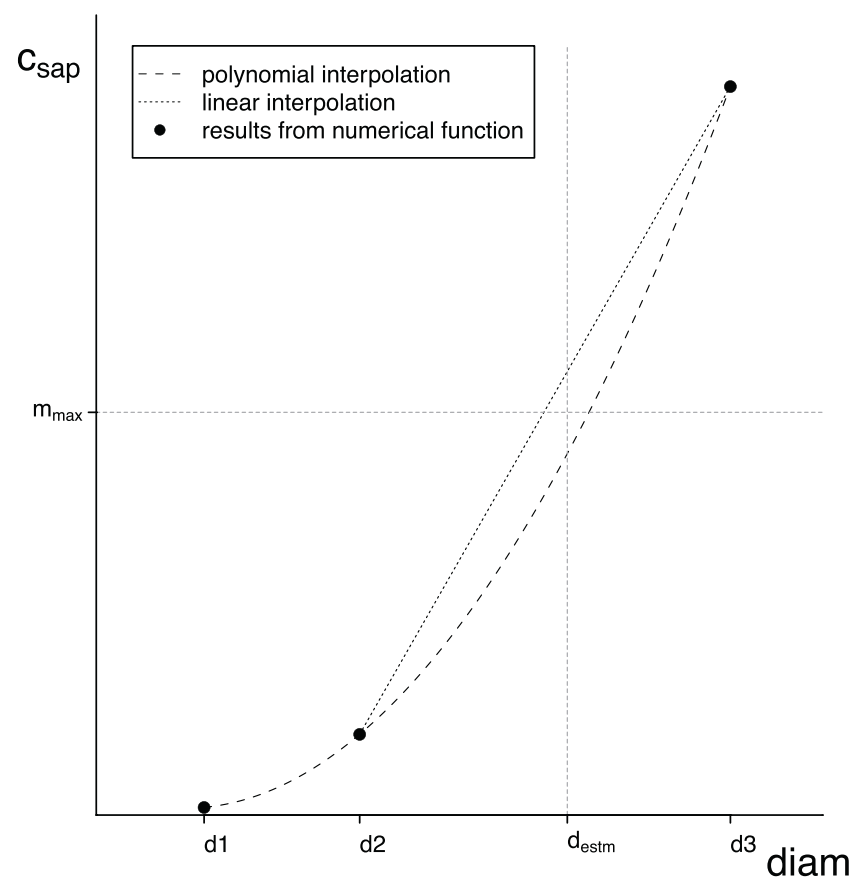

Fig. C.2. Polynomial interpolation to calculate new sapwood mass. diam: tree diameter. $c_{\text {sap }}$ : sapwood carbon mass. d1-d3: results of numerical function. $d_{\text {estm }}$ : diameter of trees in new height class. $m_{\max }$ : maximal possible $c_{\text {sap }}$ at $d_{\text {estm }}$ following LPJ-GUESS allometry. If $c_{\text {sap }}$ at $d_{\text {estm }}$ equals $m_{\max }$ the tree consists only of sapwood, and of no heartwood. A linear interpolation can lead to unrealistic trees with a sapwood mass larger than the tree mass.

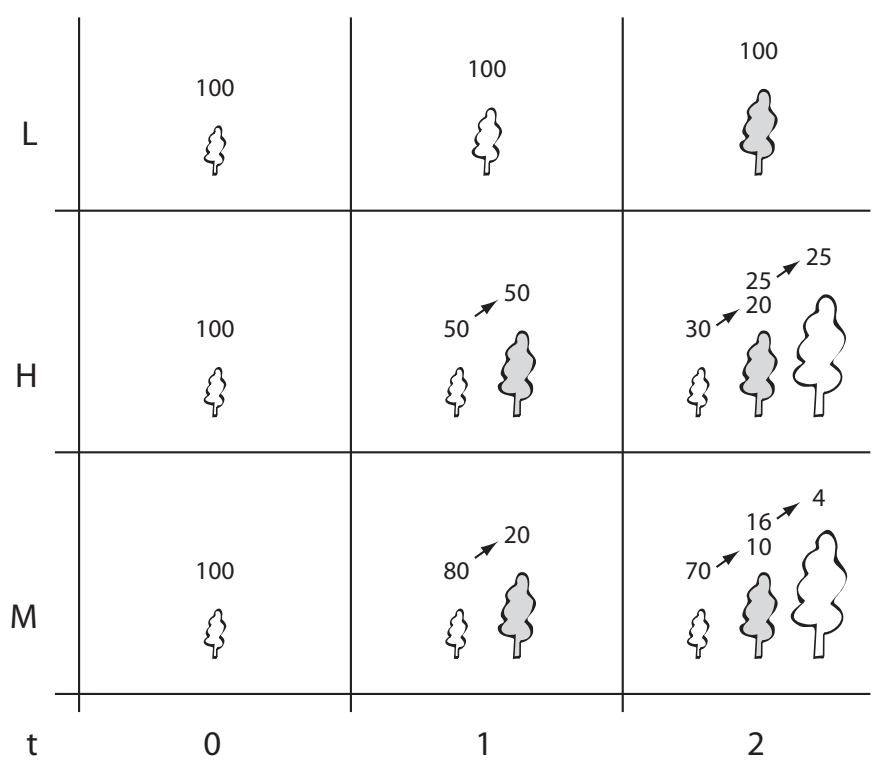

Fig. C.3. Schematic principle of different growth types. L: LPJ-GUESS growth. $H$ height class based growth with number of individuals growing proportional to changes in height, as described in Fig. 1 and as used for TreeM-LPJ. M: height class based growth, as in $\mathrm{H}$ using representative individuals, but with the number of growing individuals proportional to changes in tree mass. t: time steps. Numbers stand for tree individuals of the same height. For two numbers on top of each other the sum denotes the total numbers of individuals. Arrows indicate the numbers of trees that have grown during the last growth period. The remaining trees of the original heights are located at the beginning of the arrows. To be able to compare the results better, a selected situation is illustrated here, where after two time steps with type $\mathrm{L}$, growth trees are as large as representative trees of the second height class of types $\mathrm{H}$ and $\mathrm{M}$. For better visualization, these trees are colored gray. At time 0 , all growth types start with 100 individuals of the same height. For better illustration, from then on no new individuals are established, existing individuals do not die, and type L includes no stochastic functions and therefore has a uniform growth.
Table C.1

Shade tolerance parameters. The affiliations to species are given in Table C.3. st: shade tolerant. ist: intermediate shade tolerant. si: shade intolerant.

\begin{tabular}{lllc}
\hline & st & ist & si \\
\hline $\begin{array}{l}\text { Minimum forest-floor PAR } \\
\text { for establishment }\left(\mathrm{MJ} \mathrm{m} \mathrm{m}^{-2} \mathrm{day}^{-1}\right)\end{array}$ & 1.25 & 2 & 2.5 \\
$\begin{array}{l}\text { Growth efficiency threshold } \\
\left(\mathrm{kgC} \mathrm{m}^{-2} \text { year }^{-1}\right)\end{array}$ & 0.04 & 0.08 & 0.1 \\
$\begin{array}{l}\text { Maximum establishment rate } \\
(\text { saplings m }\end{array}$ & 0.05 & 0.1 & 0.2 \\
$\begin{array}{l}\text { Recruitment shape parameter } \\
\text { after Fulton (1991a) }\end{array}$ & 2 & 6 & 10 \\
$\begin{array}{l}\text { Annual sapwood to heartwood } \\
\text { turnover rate }\left(\mathrm{y}^{-1}\right)\end{array}$ & 0.05 & 0.065 & 0.08 \\
\hline
\end{tabular}

Table C.2

Climatic range parameters. The affiliations to species are shown in Table C.3.

\begin{tabular}{cll}
\hline & Boreal & Temperate \\
\hline Optimal temperature range for photosynthesis $\left({ }^{\circ} \mathrm{C}\right)$ & 10 to 25 & 15 to 25 \\
Maximum temperature range for photosynthesis $\left({ }^{\circ} \mathrm{C}\right)$ & -4 to 38 & -2 to 38 \\
\hline
\end{tabular}

Table C.3

Specific tree parameters. b: boreal. t: temperate. st: shade tolerant. ist: intermediate shade tolerant. si: shade intolerant. k_latosa: ratio of leaf area to sapwood crosssectional area. rootdist_u and rootdist_l: proportion of roots extending into upper and lower soil layer. chill_b: changed chilling parameter (Sykes et al., 1996). d_tol: drought tolerance, lower values show higher tolerance (minimum soil water content needed for establishment, averaged over the growing season and expressed as a fraction of available water holding capacity, and water uptake efficiency). gdd5min: minimum growing degree day sum on $5{ }^{\circ} \mathrm{C}$ base, tcmax_e and tcmin_e: minimum and maximum 20-year coldest month mean temperature for establishment. tcmin_s: maximum 20-year coldest month mean temperature for survival. L.dec: Larix decidua. P.abi: Picea Abies. P.cem: Pinus cembra. P.mon: Pinus Montana. P.syl: Pinus sylvestris. B.pen: Betula pendula. C.bet: Carpinus betulus. C.ave: Coryllus avelanna. F.syl: Fagus sylvatica. F.exc: Fraxinus excelsior. Q.rob: Quercus robur. Q.pub: Quercus pubescens. T.cor: Tilia cordata. ${ }^{\mathrm{a}}$ newly added species.

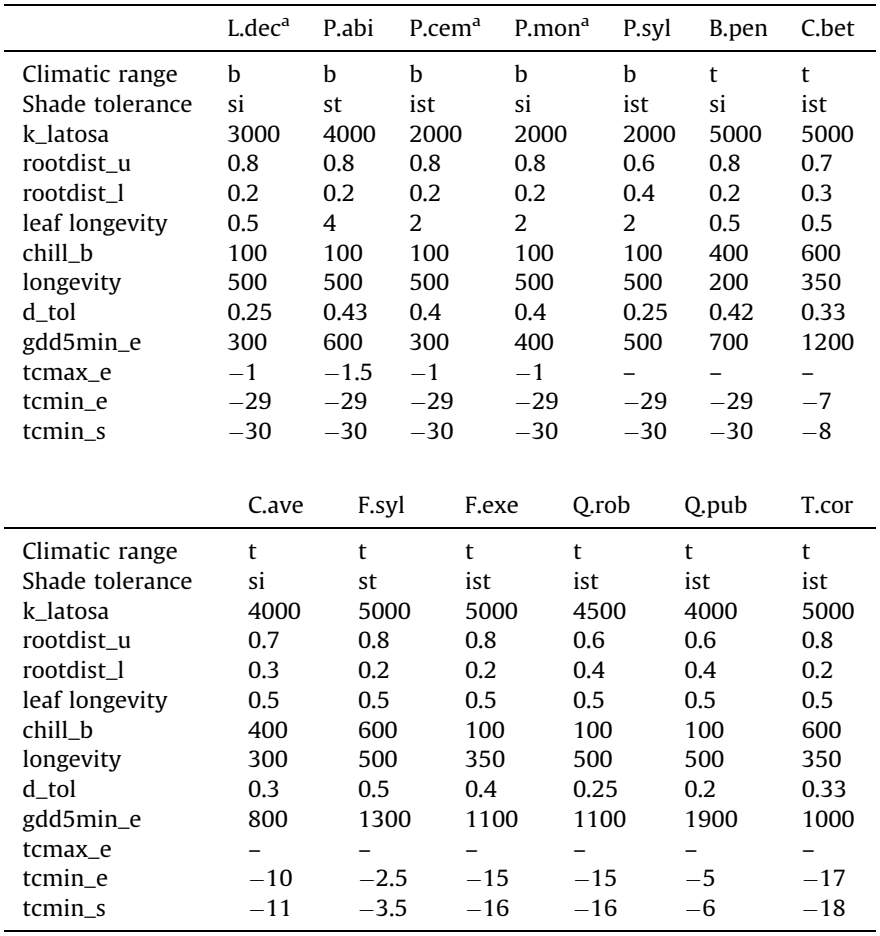




\section{References}

Bigler, C., Braker, O.U., Bugmann, H., Dobbertin, M., Rigling, A., 2006. Drought as an inciting mortality factor in Scots pine stands of the Valais, Switzerland. Ecosystems 9 (3) 330-343.

Botkin, D.B., Wallis, J.R., Janak, J.F., 1972. Some ecological consequences of a computer model of forest growth. J. Ecol. 60 (3) 849.

Brändli, U.-B. (Ed.), 2009. Schweizerisches Landesforstinventar. Ergebnisse der dritten Erhebung 2004-2006. Birmensdorf, Eidgenössische Forschungsanstalt für Wald, Schnee und Landschaft. Bundesamt für Umwelt, Wald und Landschaft, Bern.

Bugmann, H., 1994. On the ecology of mountainous forests in a changing climate: a simulation study (Ph.D. Thesis) Swiss Federal Institute of Technology.

Bugmann, H., Cramer, W., 1998. Improving the behaviour of forest gap models along drought gradients. For. Ecol. Manage. 103 (2-3) 247-263.

Bugmann, H.K.M., 1996. A simplified forest model to study species composition along climate gradients. Ecology 77 (7) 2055-2074.

Chertov, O., Komarov, A., Loukianov, A., Mikhailov, A., Nadporozhskaya, M., Zubkova, E., 2006. The use of forest ecosystem model EFIMOD for research and practical implementation at forest stand, local and regional levels. Ecol. Model. 194 (1-3) 227-232.

Chertov, O.G., Komarov, A.S., Tsiplianovsky, A.M., 1999. A combined simulation model of Scots pine, Norway spruce and Silver birch ecosystems in the European boreal zone. For. Ecol. Manage. 116 (1-3) 189-206.

Crookston, N.L., Rehfeldt, G.E., Dixon, G.E., Weiskittel, A.R., 2010. Addressing climate change in the forest vegetation simulator to assess impacts on landscape forest dynamics. For. Ecol. Manage. 260 (7) 1198-1211.

Epstein, H.E., Yu, Q., Kaplan, J.O., Lischke, H., 2007. Simulating future changes in Arctic and subarctic vegetation. Comput. Sci. Eng. 9 (4) 12-23.

Frei, E., 1976. Landwirtschafliche Bodeneignungskarte der Schweiz. Eidg. Drucksachen- und Materialzentrale.

Fulton, M.R., 1991a. Adult recruitment as a function of juvenile growth-rate in sizestructured plant-populations. Oikos 62 (1) 102-105.

Fulton, M.R., 1991b. A computationally efficient forest succession model - design and initial tests. For. Ecol. Manage. 42 (1-2) 23-34.

Gerten, D., Schaphoff, S., Haberlandt, U., Lucht, W., Sitch, S., 2004. Terrestrial vegetation and water balance - hydrological evaluation of a dynamic global vegetation model. J. Hydrol. 286 (1-4) 249-270.

Gilmore, D.W., Seymour, R.S., 1996. Alternative measures of stem growth efficiency applied to Abies balsamea from four canopy positions in central Maine, USA. For. Ecol. Manage. 84 (1-3) 209-218.

Gritti, E.S., Smith, B., Sykes, M.T., 2006. Vulnerability of Mediterranean basin ecosystems to climate change and invasion by exotic plant species. J. Biogeogr. 33 (1) $145-157$.

Haxeltine, A., Prentice, I.C., 1996a. In: Proceedings of the 1st Science Conference of the Global Analysis, Interpretation and Modelling Task Force, Garmisch Partenkirchen, Germany, pp. 693-709.

Haxeltine, A., Prentice, I.C., 1996b. A general model for the light-use efficiency of primary production. Funct. Ecol. 10 (5) 551-561.

Hickler, T., Fronzek, S., Araujo, M.B., Schweiger, O., Thuiller, W., Sykes, M.T., 2009. An ecosystem model-based estimate of changes in water availability differs from water proxies that are commonly used in species distribution models. Global Ecol. Biogeogr. 18 (3) 304-313.

Hickler, T., Smith, B., Sykes, M.T., Davis, M.B., Sugita, S., Walker, K., 2004. Using a generalized vegetation model to simulate vegetation dynamics in northeastern USA. Ecology 85 (2) 519-530.

Hickler, T., Vohland, K., Feehan, J., Miller, P., Smith, B., Costa, L., Giesecke, T., Fronzek, S., Carter, T., Cramer, W., Kühn, I., Sykes, M., 2012. Projecting the future distribution of European potential natural vegetation zones with a generalized, tree species-based dynamic vegetation model. Global Ecol. Biogeogr.

Koca, D., Smith, B., Sykes, M.T., 2006. Modelling regional climate change effects on potential natural ecosystems in Sweden. Clim. Change 78 (2-4) 381-406.

Krinner, G., Viovy, N., de Noblet-Ducoudre, N., Ogee, J., Polcher, J., Friedlingstein, P., Ciais, P., Sitch, S., Prentice, I.C., 2005. A dynamic global vegetation model for studies of the coupled atmosphere-biosphere system. Global Biogeochem. Cycles 19 (1) 44.

Lischke, H., Bolliger, J., Seppelt, R., 2006a. Dynamic spatio-temporal landscape models. Landsc. Ecol. 23 (9) 283-306.

Lischke, H., Löffler, T.J., 2006. Intra-specific density dependence is required to maintain species diversity in spatio-temporal forest simulations with reproduction. Ecol. Model. 198 (3-4) 341-361.
Lischke, H., Löffler, T.J., Fischlin, A., 1998. Aggregation of individual trees and patches in forest succession models: capturing variability with height structured, random, spatial distributions. Theor. Popul. Biol. 54 (3) 213-226.

Lischke, H., Zimmermann, N.E., Bolliger, J., Rickebusch, S., Löffler, T.J., 2006b. Treemig: a forest-landscape model for simulating spatio-temporal patterns from stand to landscape scale. Ecol. Model. 199 (4) 409-420.

Löffler, T.J., Lischke, H., 2001. Incorporation and influence of variability in an aggregated forest model. Nat. Resource Model. 14 (1) 103-137.

Miller, P.A., Giesecke, T., Hickler, T., Bradshaw, R.H.W., Smith, B., Seppa, H., Valdes, P.J., Sykes, M.T., 2008. Exploring climatic and biotic controls on Holocene vegetation change in Fennoscandia. J. Ecol. 96 (2) 247-259.

Mitchell, T., Carter, R., Jones, P., Hulme, M., New, M., 2004. A comprehensive set of high-resolution grids of monthly climate for Europe and the globe: the observed record (1901-2000) and 16 scenarios (2001-2100). Tech. Rep.

Monsi, M., Saeki, T., 1953. Über den Lichtfaktor in den Pflanzengesellschaften und seine Bedeutung für die Stoffproduktion. Jpn. J. Bot. 14, 22-52.

Moorcroft, P.R., Hurtt, G.C., Pacala, S.W., 2001. A method for scaling vegetation dynamics: the ecosystem demography model(ed). Ecol. Monogr. 71 (4) 557-585

O'Hara, K.L., Lahde, E., Laiho, O., Norokorpi, Y., Saksa, T., 1999. Leaf area and tree increment dynamics on a fertile mixed-conifer site in southern Finland. Ann. For. Sci. 56 (3) 237-247.

Prentice, I.C., Sykes, M.T., Cramer, W., 1993. A simulation-model for the transient effects of climate change on forest landscapes. Ecol. Model 65 (1-2) 51-70.

Sato, H., Itoh, A., Kohyama, T., 2007. SEIB-DGVM: a new dynamic global vegetation model using a spatially explicit individual-based approach. Ecol. Model. 200 (3-4) 279-307.

Scherstjanoi, M., Kaplan, J.O., Thürig, E., Lischke, H., 2013. GAPPARD: a computationally efficient method of approximating gap-scale disturbance in vegetation models. Geosci. Model Dev. Discuss. 6, 1021-1048.

Schober, R., 1987. Ertragstafeln wichtiger Baumarten bei verschiedener Durchforstung, 3rd edition. Sauerländer, Frankfurt am Main.

Schroeder, P.E., McCandish, B., Waring, R.H., Perry, D.A., 1982. The relationship of maximum canopy leaf area to forest growth in eastern Washington, USA Northwest Sci. 56 (2) 121-130.

Seidl, R., Rammer, W., Scheller, R.M., Spies, T.A., 2012. An individual-based process model to simulate landscape-scale forest ecosystem dynamics. Ecol. Model. 231, 87-100.

Shinozaki, K., Yoda, K., Hozumi, K., Kira, T., 1964. A quantitative analysis of plant form - the pipe model theory. I. Basic analyses. Jpn. J. Ecol. 14, 97-105.

Shugart, H.H., 1984. A Theory of Forest Dynamics. The Ecological Implications of Forest Succession Models Springer, New York.

Shugart, H.H., West, D.C., 1977. Development of an Appalachian deciduous forest succession model and its application to assessment of impact of chestnut blight. J. Environ. Manage. 5 (2) 161-179.

Sitch, S., Smith, B., Prentice, I.C., Arneth, A., Bondeau, A., Cramer, W., Kaplan, J.O. Levis, S., Lucht, W., Sykes, M.T., Thonicke, K., Venevsky, S., 2003. Evaluation of ecosystem dynamics, plant geography and terrestrial carbon cycling in the LPJ dynamic global vegetation model. Global Change Biol. 9 (2) 161-185.

Smith, B., Knorr, W., Widlowski, J.L., Pinty, B., Gobron, N., 2008. Combining remote sensing data with process modelling to monitor boreal conifer forest carbon balances. For. Ecol. Manage. 255 (12) 3985-3994.

Smith, B., Prentice, I.C., Sykes, M.T., 2001. Representation of vegetation dynamics in the modelling of terrestrial ecosystems: comparing two contrasting approaches within European climate space. Global Ecol. Biogeogr. 10 (6) 621-637.

Strigul, N., Pristinski, D., Purves, D., Dushoff, J., Pacala, S., 2008. Scaling from trees to forests: tractable macroscopic equations for forest dynamics. Ecol. Monogr. 78 (4) 523-545.

Sykes, M.T., Prentice, I.C., Cramer, W., 1996. A bioclimatic model for the potential distributions of north European tree species under present and future climates. J. Biogeogr. 23 (2) 203-233.

Waring, R.H., 1985. Imbalanced forest ecosystems - assessments and consequences For. Ecol. Manage. 12 (2) 93-112.

Wilby, R., Charles, S., Zorita, E., Timbal, B., Whetton, P., Mearns, L.O., 2004. Guidelines for use of climate scenarios developed from statistical downscaling methods. Tech. Rep. IPCC Task Group on data and scenario support for Impact and Climate Analysis (TGICA).

Wolf, A., Blyth, E., Harding, R., Jacob, D., Keup-Thiel, E., Goettel, H., Callaghan, T., 2008. Sensitivity of an ecosystem model to hydrology and temperature. Clim. Change 87 (1-2) 75-89.

Yang, J., He, H.S., Shifley, S.R., Thompson, F.R., Zhang, Y.J., 2011. An innovative computer design for modeling forest landscape change in very large spatial extents with fine resolutions. Ecol. Model. 222 (15) 2623-2630. 